\title{
SEISMIC DESIGN FOR TORSIONAL RESPONSE OF DUCTILE BUILDINGS

\author{
T. Paulay
}

\begin{abstract}
SUMMARY
A simple approach to the consideration of torsional effects in the seismic design of ductile building structures is postulated. Instead of increasing torsional strength, the control of twist, which may amplify local inelastic translational deformations, is emphasised. This may be achieved by assuring that some residual torsional stiffness of the system is available. A number of examples illustrate the simple principles involved. It is demonstrated that traditional codified techniques, based on the evaluation of torsional effects in elastic systems, are largely irrelevant to ductile structural response. It is recommended that, in accord with the philosophy of capacity design, torsional response should be controlled by elastic elements, while hysteretic damping is derived from inelastic translational mechanisms. As a general rule critical conditions for torsional response of well proportioned structures are likely to arise only when inelastic displacements are imposed in a narrow band of directions diagonal to the principal reference axes of orthogonal systems. It is suggested that in the presence of significant eccentricities the displacement ductility demand on the system should be reduced. Thereby elements with defined ductility capacity can be protected against excessive imposed inelastic deformations. The presentation addresses primarily concepts of torsional behaviour rather than advancement in analytical techniques.
\end{abstract}

\section{INTRODUCTION}

Issues relevant to torsion introduced by lateral forces, particularly in multi-storey buildings, offered challenges to researchers as well as code writers over many years. In some form or another, several of the findings have been incorporated in building codes of the world and are now routinely used.

Most of these approaches, including that of NZS 4203 [1], are based on elastic structural response. However, the design of the majority of building structures located in areas with significant seismic risk, relies on inelastic response when earthquake excitations corresponding to the specified ultimate limit state is considered. Hence the relevance of current code recommendations, based on elastic torsional response, is open to questions.

To allow the contrast between elastic and ductile torsional response to be appreciated, first existing typical design procedures, together with relevant principles and terminology, are briefly summarised. Subsequently the perceived features associated with ductile response during significant seismic excitations are presented. Some examples, generally simplified to aid recognition of fundamental issues involved, are used to show effects of twisting of the structure on the ductility demands affecting the principal lateral force- resisting vertical elements.

Subsequently conclusions are drawn from this study and suggestions are made for the use of a design approach that is

1 Emeritus Professor of Civil Engineering, University of Canterbury, Christchurch, New Zealand, (Life Member) claimed to be rational, very simple and in better accord with the philosophy of displacement control and capacity design.

It may be recalled that the major prerequisites of capacity design are:

- The establishment of a viable and kinematically admissible plastic mechanism.

- The determination of a strength hierarchy that will ensure that inelastic deformations, required to enable the intended displacement ductility demand to be met, occur at predetermined and appropriately constructed locations. Thereby all other elements of the structure are assured to respond within the elastic domain of response.

It is postulated that, as a general rule, the same approach should be applied to building systems, whereby the torsional response of the building should preferably remain in the elastic domain, while the desired system ductility is being derived from inelastic translational displacements of suitable elements.

\section{ELASTIC TORSIONAL RESPONSE}

\subsection{The Traditional Procedure}

Traditional considerations of torsional effects in elastic building systems are briefly summarised with the aid of Figure 1. To allow focusing on basic issues and for the sake of simplicity, the illustrations used show only wall elements to which the total lateral force-resistance has been assigned. Modifications 
necessary when considering buildings where lateral force resistance relies on frames alone, are briefly considered in Section 5 .

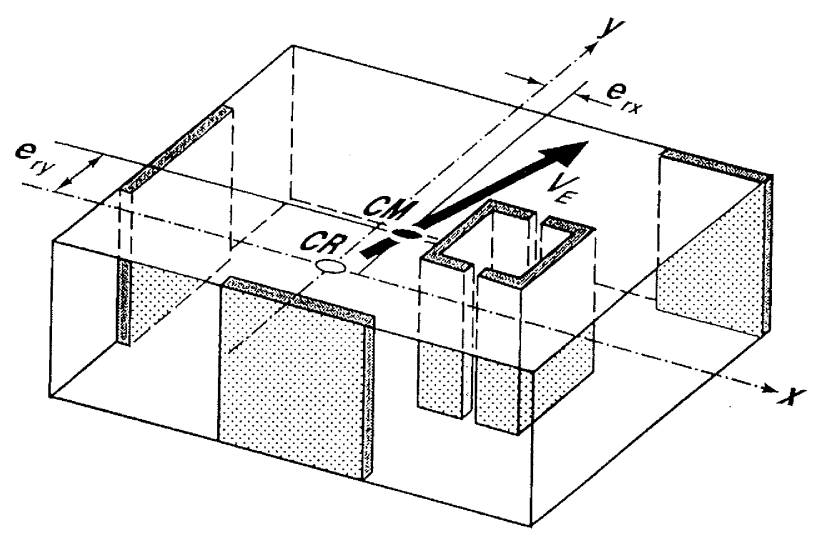

FIGURE 1 Typical arrangement of lateral force resisting vertical elements.

During seismic excitations the induced inertia force at any level, $\mathrm{V}_{\mathrm{E}}$, is assumed to act at the "centre of mass", shown as CM in Figure 1. The storey shear and the mass refer to the total above the level considered. Although actions due to torsional inertia may also be generated, those are assumed to be wholly absorbed by elastic elements of preferred systems, and will not be considered here.

Standard procedures are available [2] to determine the actions within elastic structures resulting from the application of substitute static forces. Such analyses necessitate the establishment of the "centre of rigidity", $\mathrm{CR}$, often also termed "centre of stiffness" or "shear centre" or "centre of twist". It is the location at which a storey shear force, such as $V_{E}$, applied to the elastic structure in any direction, will produce inter-storey translations only. The distance measured from "the centre of rigidity" to the "centre of mass", as shown in Figure 1, for convenience subsequently defined in this text by the symbols CR and CM, respectively, is the stiffness eccentricity. This is usually resolved into components with respect to the reference axes, $x$ and $y$. With the superposition of the effects of corresponding components of storey shear forces, resulting from storey translations and storey twist, actions to be developed in each elastic lateral force carrying vertical member are readily found [2].

Eccentricities so derived, shown as $e_{r x}$ and $e_{r y}$ in Figure 1, are usually adjusted for accidental effects, such as may result from uncertainties in estimating the location of both $\mathrm{CR}$ and $\mathrm{CM}$, and possible torsional input motions of the floor masses.

\subsection{Restrictions on Twist}

The results of this approach are expected to ensure that the design shear force assigned to each lateral force-resisting vertical element is in excess of that expected to occur during the elastic response of the building. When the analysis described above is used, certain limitations in terms of horizontal regularity of the system are also imposed [1] on the magnitudes of the eccentricities which were derived with the use of stiffness properties. Accordingly in New Zealand the following criteria [1] are expected to be satisfied:
- The distance at any level between $\mathrm{CR}$ and $\mathrm{CM}$, relevant to all masses above that level, shown in Figure 1, should neither exceed 0.3 times the maximum plan dimension of the structure at that level, measured perpendicularly to the applied lateral force, nor change its sign over the height of the building, or,

- Under the action of equivalent static lateral forces, the ratio of the horizontal displacements at the ends of the axis transverse to the direction of the applied force, $\Delta_{\mathrm{a}}$ and $\Delta_{\mathrm{b}}$, should be in the range of $3 / 7$ and $7 / 3$. This criterion, presumably making allowances for a desired minimum value of the torsional stiffness, $\mathrm{K}_{\mathrm{t}}$, is illustrated in Figure 2.

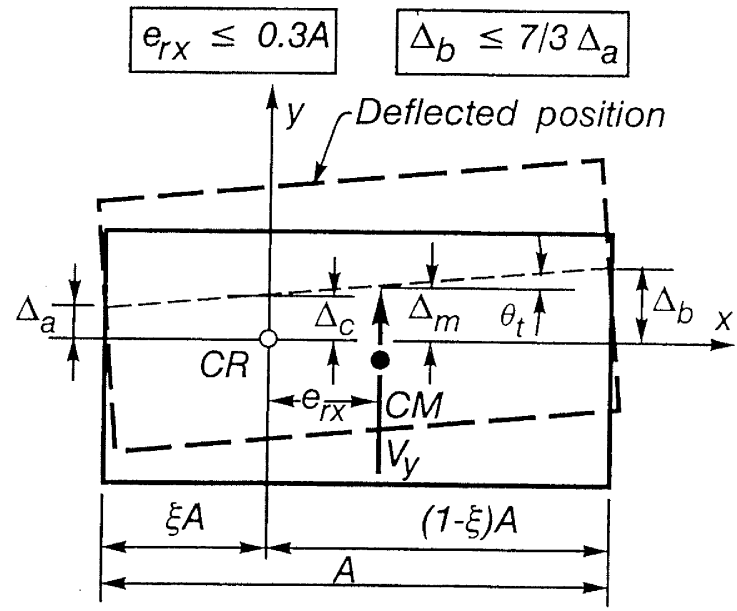

FIGURE 2 Restrictions on the computed eccentricity and angle of twist for elastic systems [1].

Using geometrical relationships obtainable from Figure 2, two unexpected results emerge for the second criterion given above. It is found that the angle of twist is limited to:

$$
\theta_{\mathrm{t}} \leq \frac{4 \Delta_{\mathrm{c}}}{(3+4 \xi) \mathrm{A}}
$$

This implies that increased translational stiffness, resulting in reduced translational displacement, $\Delta_{c}$, requires also increased torsional stiffness to be provided to achieve a proportional reduction of the angle of twist $\theta_{\mathrm{t}}$. On the other hand, the angle of twist is permitted to be increased, as the width of the structure, $\mathrm{A}$, is reducing. The relevance of these requirements to ductile response will be examined subsequently.

Similar restrictions with respect to twist control in elastic systems have been recommended in Japan $[2,5]$, whereby the ratio of the eccentricities and the radii of gyration of storey stiffnesses should be limited so that

and

$$
\begin{aligned}
& \mathrm{e}_{\mathrm{rx}} / \mathrm{r}_{\mathrm{kx}}<0.15 \\
& \mathrm{e}_{\mathrm{ry}} / \mathrm{r}_{\mathrm{ky}}<0.15
\end{aligned}
$$

where $e_{r x}$ and $e_{r y}$ are stiffness eccentricities as shown in Figure 1 , and

$$
\begin{aligned}
& \mathrm{r}_{\mathrm{kx}}=\sqrt{ }\left(\mathrm{K}_{\mathrm{t}} / \Sigma \mathrm{k}_{\mathrm{yi}}\right) \\
& \mathrm{r}_{\mathrm{ky}}=\sqrt{ }\left(\mathrm{K}_{\mathrm{t}} / \Sigma \mathrm{k}_{\mathrm{xi}}\right)
\end{aligned}
$$


and $\mathrm{k}_{\mathrm{yi}}$ and $\mathrm{k}_{\mathrm{xi}}$ are the translational stiffnesses of vertical elements with respect to the $\mathrm{x}$ and $\mathrm{y}$ axes, respectively. The polar moment of inertia of the translational stiffnesses [2] is the torsional stiffness:

$$
\mathrm{K}_{\mathrm{t}}=\Sigma \mathrm{x}_{\mathrm{i}}^{2} \mathrm{k}_{\mathrm{yi}}+\Sigma \mathrm{y}_{\mathrm{i}}^{2} \mathrm{k}_{\mathrm{xi}}
$$

where $\mathrm{x}$ and $\mathrm{y}$ are the co-ordinates of a wall element with respect to $\mathrm{CR}$.

The relevance to ductile response of these requirements are examined in Section 3.6.

Other codes [6] take the sophistication involved in approximate torsional analyses a step further. Accordingly the limits of design eccentricities, measured from $\mathrm{CR}$, include also a term considered to allow for dynamic effects resulting from simultaneous translational and torsional vibrations.

It will be shown subsequently that the requirement [1] whereby the eccentricity with respect to CR should not exceed 0.3 times the relevant plan dimension of the building, is an important one. Large stiffness eccentricities result in large differences between strength to stiffness ratios for lateral force resisting components, a parameter significantly affecting relative component ductility demands, as discussed in Section 3.9.

When more involved, and presumably more reliable, analysis techniques are used, the above limitations need not apply [1]. These restrictions on eccentricities tacitly assume that the needs of inelastic seismic response, in particular ductility demands on affected lateral force resisting vertical elements, have been catered for. One of the aims of the discussions that follow, is to examine the relevance and effectiveness of such "elastic" analyses in advancing desirable inelastic seismic response.

\subsection{Definition of System Stiffness and Yield Displacement}

For the purpose of estimating the fundamental period of vibration of a structural system and the absolute value of the displacement at the assumed ultimate seismic limit state, the system stiffnesses and yield displacements, respectively, with reference to particular directions of the base shear need to be defined. For convenience it is common practice to assume that the system stiffness with respect to lateral forces can be based on the sum of the stiffness of the elements. However, in seismic design the system stiffness should be based on the lateral displacement, $\Delta_{\mathrm{m}}$, of the centre of mass (Figure 2). Thus the system stiffness, $K_{s}$, should relate the lateral force, $V$, to the elastic displacement at $\mathrm{CM}$, i.e., $\mathrm{K}_{\mathrm{s}}=\mathrm{V} / \Delta_{\mathrm{m}}$. The component displacements are:

$$
\Delta_{\mathrm{m}}=\Delta_{\mathrm{m}}^{\prime}+\Delta_{\mathrm{m}}^{\prime \prime}=\mathrm{V} / \mathrm{\Sigma \textrm {k } _ { \mathrm { i } }}+\theta_{\mathrm{t}} \mathrm{e}_{\mathrm{r}}
$$

where from equation (2e) $\theta_{\mathrm{t}}=\mathrm{e}_{\mathrm{r}} \mathrm{V} / \mathrm{K}_{\mathrm{t}}$

Therefore $\quad \Delta_{\mathrm{m}}=\frac{\mathrm{V}}{\Sigma \mathrm{k}_{\mathrm{i}}}+\frac{\mathrm{e}_{\mathrm{r}}^{2} \mathrm{~V}}{\mathrm{~K}_{\mathrm{t}}}$

Therefore, the stiffness of the system, for example that relevant to a base shear in the $\mathrm{y}$ direction of the structure shown in Figure 2, is

$$
\mathrm{K}_{\mathrm{sy}}=\frac{\sum \mathrm{k}_{\mathrm{yi}}}{1+\left(\mathrm{e}_{\mathrm{rx}} / \mathrm{r}_{\mathrm{kx}}\right)^{2}}
$$

where $r_{k x}$ is defined by equation (2c) and the stiffness eccentricity, $e_{r x}$, with respect to CM is shown in Figure 1. The yield displacement with respect to the principal directions, $\mathrm{x}$ and $y$, may then be derived from equation (3a) once the base shear assumed to lead to the maximum elastic displacement in that direction is defined. Definitions of yield displacements, used as references to enable displacement ductilities to be quantified, can be identified in Fig. 8.

From the superposition of elastic deflections in the $x$ and $y$ direction, those associated with a skew base shear, such as shown in Figure 1, may also be derived. The simultaneous onset of yielding in elements resisting lateral forces in the $\mathrm{x}$ and $y$ directions (Figure 1), will be associated with a unique value of the angle, $\alpha$, of the base shear. The skew yield displacement will be larger than those relevant to the principal directions. However, the base shear resistance in this particular direction will also be larger. Therefore, the system stiffness associated with seismic attack in a direction defined by $\alpha, \mathrm{K}_{\mathrm{s} \alpha}$, will be within the limits of $\mathrm{K}_{\mathrm{sx}}$ and $\mathrm{K}_{\mathrm{sy}}$, respectively. It is not recommended that this degree of sophistication, relevant to skew seismic attack, be considered in seismic design of buildings.

\section{INELASTIC SEISMIC RESPONSE}

\subsection{Aims of the Design Strategy}

In the design of structures intended to respond in a ductile manner during a major seismic event, the relationship between inelastic deformations of elements and possible torsional actions should be considered. As a general rule, this is not done. In routine design, with the use of lateral static design forces, torsional actions are estimated only for elastically responding systems, as outlined in Section 2. In the expectation that this is also representative of conditions at the ultimate limit state, the strength of elements is determined for the most adverse combination of actions resulting from elastic translational and torsional displacements.

Performance criteria for inelastic structures affected by torsional response may be formulated thus:

- Earthquake imposed deformations, including system twist, should be such as to limit the ductility demand on any element to its defined ductility capacity.

- Magnitudes of ultimate interstorey displacements expected at locations remote from the centre of twist, should not exceed those considered acceptable, typically $2.5 \%$ of the storey height.

The purpose of considering torsion in the design of ductile systems should be, therefore, to account for inelastic displacements, including twist of the system rather than to provide torsional resistance. The word "twist" is used deliberately in this context. It intends to emphasise the primary need to address torsion-induced displacement demands on critical elements. Using the properties of elements as detailed, actions generated at this ultimate limit state can be predicted with relative ease.

\subsection{Response Comparisons}

With the comparison of elastic and inelastic building systems subjected to twist as a result of the application of lateral static forces, a number of differences emerge. To illustrate these, a 
few, somewhat idealised, examples will be used. Although the principles involved are valid for any type of ductile structure that may be used for multistorey buildings, for the sake of simplicity and to underline pertinent concepts, systems will be considered in which the entire lateral force resistance has been assigned to prismatic rectangular reinforced concrete cantilever walls, (Figure 1). Full wall base restraint, in-plane wall strength only and interconnection at all levels by infinitely rigid diaphragms are assumed.

Because the ultimate displacement of the system, $\Delta_{u}$, is also a good measure of the total energy dissipation, it should be taken as that at CM. System displacement ductility, $\mu_{\Delta}$, can then be quantified as the ratio of ultimate and yield displacements at that point.

\subsection{Torsional Restraint}

Figure 3a illustrates an example extensively used by researchers for the study of the dynamic coupled translational and torsional response of elastic systems with respect to the $y$ axis. Symmetry, in terms of both strength and stiffness, with respect to actions along the y axis implies that in this example each wall should resist one half of the total lateral seismic design force, $\mathrm{V}_{\mathrm{E}}$. In the absence of identifiable eccentricities, this structure is commonly referred to as "torsionally balanced". Nevertheless, in accordance with typical code [1] requirements, a design eccentricity of $\mathrm{e}_{\mathrm{dx}}= \pm 0.1 \mathrm{~A}$, to allow for accidental or unpredictable torsional effects, is usually also considered. This step, instead of providing torsional resistance, will simply increase the translational resistance of this example structure to $1.25 \mathrm{~V}_{\mathrm{E}}$.

With the imposition on the real structure of inelastic translational deformations in the $y$ direction, the elements are no longer capable of resisting any additional forces, such as due to torsion. Any torque which may be generated will result in an immediate reduction in lateral force resistance. Quantification of this is presented in Section 3.10. It is also evident that once elements have entered the inelastic domain, the torsional stiffness, $K_{t}$, of the system, and hence the control over twisting, vanishes. The term "torsional restraint" is introduced to describe the degree of control provided by some elastic elements in the system of twist, resulting from non-uniform inelastic deformations of translatory elements.

\subsection{Torsionally Unrestrained Systems}

Using the example structure shown in Figure 3 the restrictions on the ductility capacity of the system are considered in this section. The yield displacement of the system, $\Delta_{y}$, is in this case the same as that of the identical Walls (1) and (2).

The strengths of the walls, as constructed, cannot be developed simultaneously during an earthquake imposed displacement. A small excess of strength, for example of Wall (1) in comparison with that of Wall (2), will lead to inelastic twisting of the system, as shown in Figure $3 \mathrm{a}$, without an ability to resist torsion.

When the intended displacement ductility demand, $\mu_{\Delta}$, measured at $\mathrm{CM}$ and quantified by the ultimate translational displacement, $\Delta_{\mathrm{u}}=\Delta_{\mathrm{y}}+\Delta_{\mathrm{p}}$, is imposed on the system, the inelastic deflection generated in Wall (2), $\Delta_{\mathrm{p} 2}$, will be in the example shown in Figure $3 \mathrm{a}$ twice that at $\mathrm{CM}, \Delta_{\mathrm{p}}$. Thus the displacement ductility factor relevant to Wall (2) will be significantly higher at:

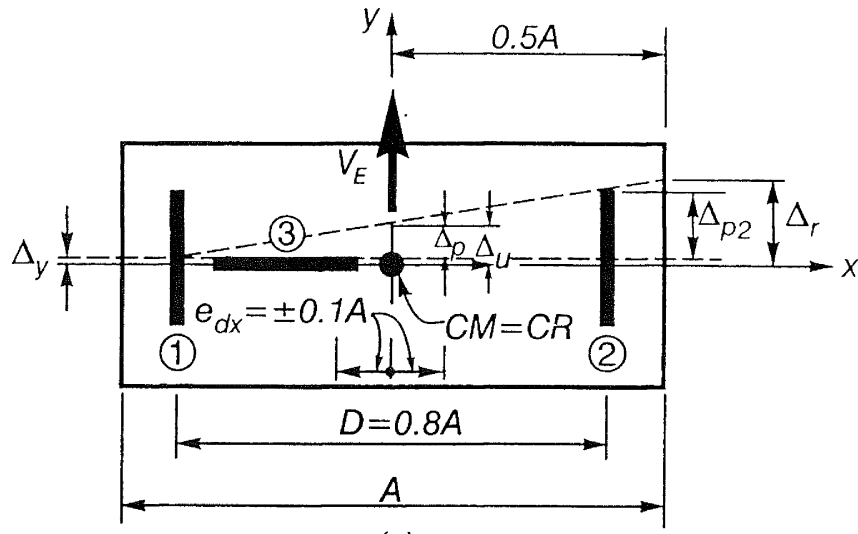

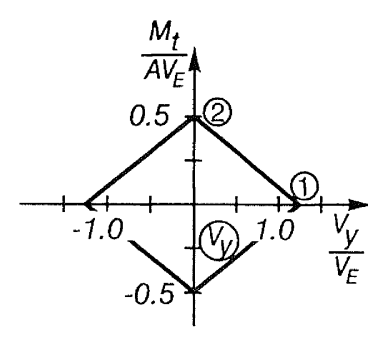

(b) (a)

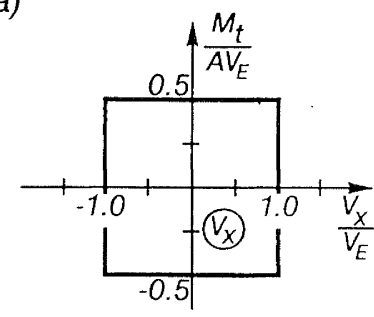

(c)

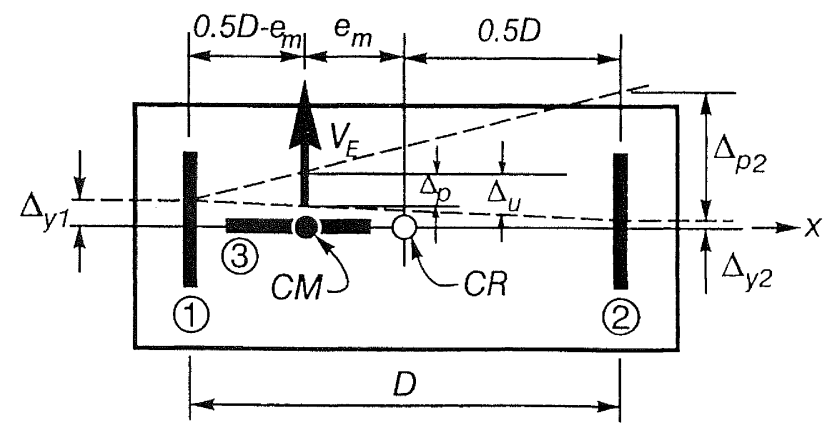

(d)

FIGURE 3 A torsionally unrestrained system when subjected to ductility demands.

$$
\mu_{2}=2 \mu_{\Delta}-1
$$

In accord with the common assumption used in New Zealand, that, with the exception relevant to short periods of vibration, earthquake-induced displacements during the fully elastic and elasto-plastic response to the same earthquake record, are the same, are assumed to be applicable also to structures considered in this study. Hence the required lateral design forces are inversely proportional to the relevant ductility factor. Thus a structure provided with some additional strength with respect to lateral design forces, can be expected to be subjected to a correspondingly reduced displacement ductility demand. For short period structures, where the "equal energy" concept is considered to be more relevant, using the relevant region of code-specified design spectra, corresponding assumptions with respect to the displacement ductility demand on the system, $\mu_{\Delta}$, may be readily made.

The maximum displacement ductility capacity of cantilever structural walls, $\mu_{\max }=\Delta_{\mathrm{u}} / \Delta_{\mathrm{y}}$, is commonly assumed [3] to be of the order of 5 . Because of the strength enhancement by 
$25 \%$, resulting from the use of code-specified torsion provisions, the ductility demand on the system shown in Figure 3 a may be assumed to be only $\mu_{\Delta}=5 / 1.25=4$. With these assumptions the displacement ductility imposed on Wall (2), according to equation (4), can be expected to be $\mu_{2}=7$. This should be considered to be excessive.

The example intends to demonstrate that the commonly used torsional provisions have in this case not achieved the presumed purpose of adequately accommodating additional deformations resulting from twisting of the system. If the ductility demand imposed by the design earthquake on the appropriately detailed Wall (2) of the example structure, is to be limited to $\mu_{\max }$, the system would need to be designed for a restricted ductility demand. This may be obtained from inverting equation (4) thus

$$
\mu_{\Delta} \leq\left(\mu_{\max }+1\right) / 2
$$

With a typical ductility capacity of a well detailed wall [3], $\mu_{\max }$ $=5$, the system ductility for the ideally symmetrical structure in Figure 3a is thus to be restricted to $\mu_{\Delta}=3$. According to a force-based seismic design approach, the magnitude of the base shear is then to be selected accordingly.

Because of symmetry no twist should develop in the elastic example structure. With some eccentricity of the mass, $e_{m}$, equation (1) would allow [1] a twist of $4 \Delta_{y} / 5 \mathrm{~A}$. This is a poor indicator of the twist at the ultimate limit state of this torsionally unrestricted system, which, as Figure 3a shows, is $\theta_{\mathrm{tu}}=\Delta_{\mathrm{p} 2} / \mathrm{D}$ $=\left(\mu_{\max }-1\right) \Delta_{\mathrm{y}} / \mathrm{D}=5 \Delta_{\mathrm{y}} / \mathrm{A}$. This is more than 6 times the angle of twist envisaged by the code [1] for an elastically responding system.

Perfect elasto-plastic response, implied in the above discussions, infers inability of plastified elements to provide any torsional restraint. Fortunately this is not the case when well detailed elements are used, because even relatively small post-yield stiffness should enable some restraining forces to be mobilised. Within limits, this feature could, and in certain cases may need to, be relied on in restricting excessive inelastic deformations of elements remote from the centre of twist.
The general case for a similar torsionally unrestricted symmetrical system is shown in Figure $3 \mathrm{~d}$. The prediction of the restriction of the system ductility capacity, $\mu_{\Delta}$, is a little more complex because the mass eccentricity, $\mathrm{e}_{\mathrm{m}}$, needs also to be considered. Using geometric relationships, similar to those shown in Figure $3 \mathrm{a}$, and assuming also that the strength of Wall (1) is slightly in excess of that required to resist the appropriate component of the base shear, $\mathrm{V}_{\mathrm{E}}$, it may be shown that the system ductility should be limited to:

$$
\mu_{\Delta} \leq \frac{\mu_{\max }-1}{1+\omega_{o}}+1
$$

where

$$
\omega_{\mathrm{o}}=\left(\frac{0.5+\mathrm{e}_{\mathrm{m}} / \mathrm{D}}{0.5-\mathrm{e}_{\mathrm{m}} 1 \mathrm{D}}\right)^{2}
$$

when element stiffnesses are identical, as in Figure 3a.

Similar relationships for torsionally unrestrained assymetric systems of the type seen in Figure 3d are summarised in Figure 4. It may be seen that for this case, ie, when $k_{1} \neq k_{2}$, equation (6b) simply modifies to:

$$
\omega_{\mathrm{o}}=\frac{\mathrm{k}_{2}}{\mathrm{k}_{1}}\left(\frac{0.5+\mathrm{e}_{\mathrm{m}} / \mathrm{D}}{0.5-\mathrm{e}_{\mathrm{m}} / \mathrm{D}}\right)^{2}
$$

when it is assumed that displacement of Wall (1) does not exceed its yield displacement, $\Delta_{\mathrm{y} 1}$. Values of $\mu_{\Delta}$ as a function of the range of variables in equation (6c), and assuming that $\mu_{\max }=5$, are shown in Figure 4. It is evident that the closer $\mathrm{CM}$ is to Wall (1) the more severe the ductility demands on Wall 2, requiring drastic reductions of $\mu_{\Delta}$. The eccentricity ratio, $e_{\mathrm{m}} / \mathrm{D}$, in the above equations is to be taken positive as shown in the insert of Figure 4.

Figure 5 shows the specific twist of the system when $\mu_{\max }=5$. This may be compared with the corresponding twist in a symmetrical system $\left(\mathrm{k}_{2} / \mathrm{k}_{1}=1\right)$ shown by the heavy line.

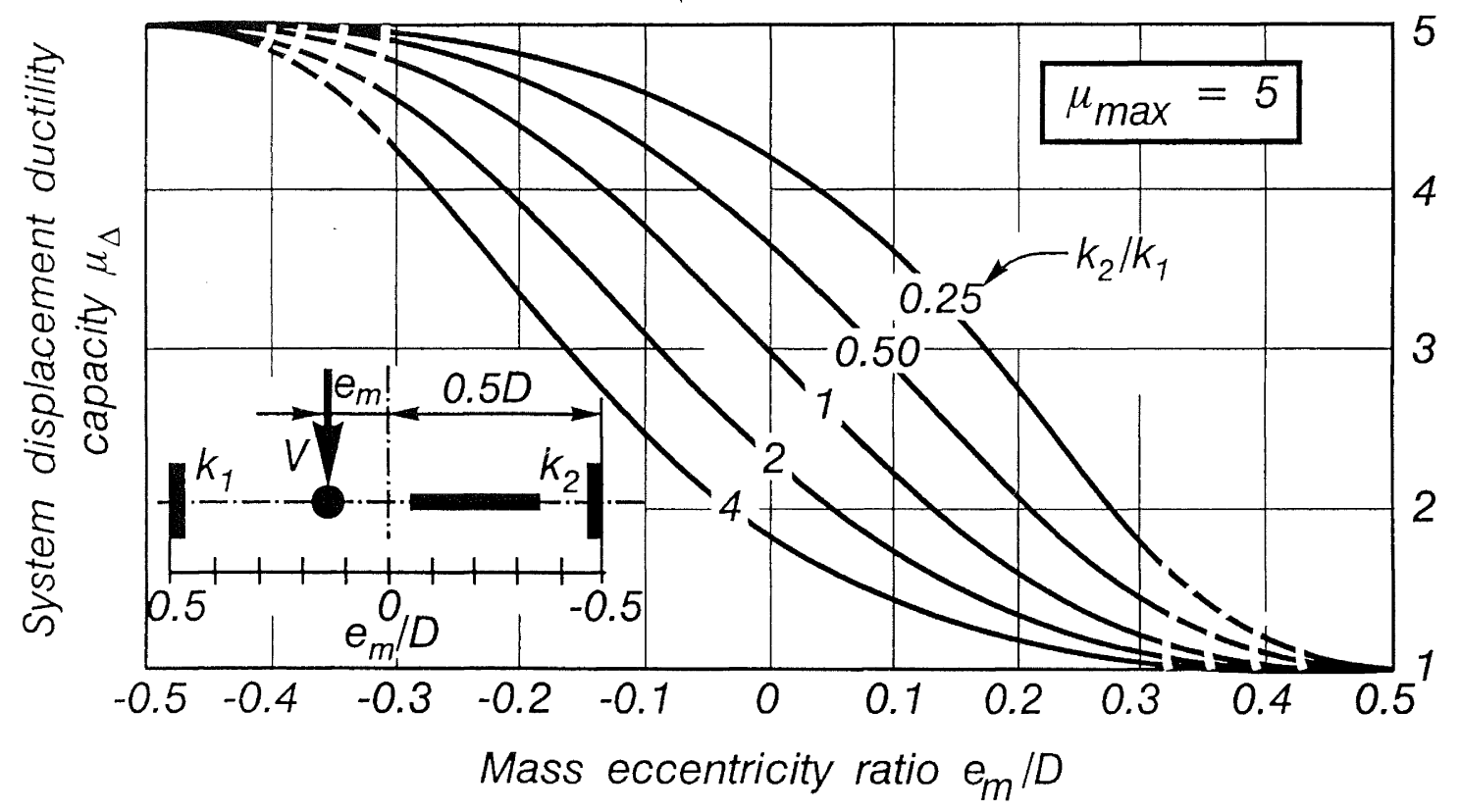

FIGURE 4 Displacement ductility capacity of torsionally unrestrained ductile systems. 


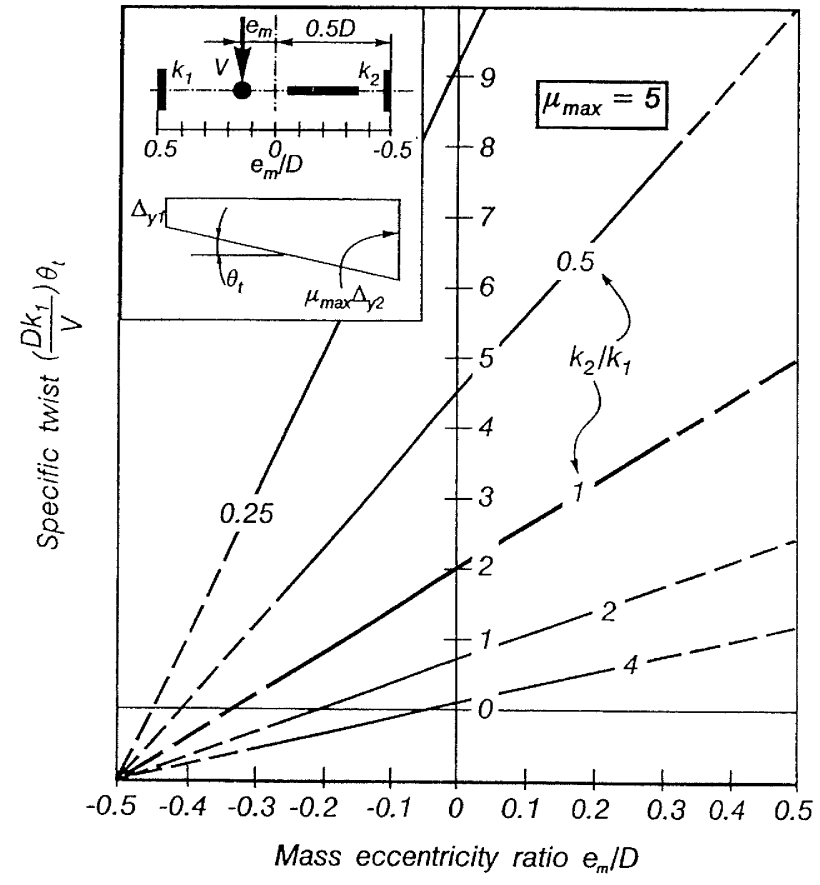

FIGURE 5 Twist developing in a torsionally unrestrained ductile system.

As stated, equations (6b) and (6c) and the results in Figures 4 and 5 are based on the assumption that the displacement of Wall (1) does not exceed its yield displacement. Therefore, the system displacement ductility capacity, $\mu_{\Delta}$, is controlled by the maximum ductility capacity, $\mu_{\max }$, of Wall (2). It may be necessary to check torsional response also with the assumption that Wall (2) will not yield. This can be readily carried out with the use of the same equations or Figures 4 and 5 and appropriate interchange of the wall indices.

It may be shown that a similar expression for the $\omega_{0}$ factor is applicable when earthquake resistance in the type of torsionally unrestrained structure shown in Figure 3, is assigned to move than two parallel elements. When only two walls exist, the share of each wall in resisting the base shear, $V_{E}$, is controlled solely by statics. However, when three or more elements contribute to base shear resistance, in addition to criteria of equilibrium, those of deformation compatibility of the elastic system need also to be considered. In this case the force to be developed in each of the parallel elements may be readily determined with the use of the established analysis reviewed in Section 2. It is then found that:

$$
\omega_{\mathrm{o}}=\frac{\mathrm{V}_{\ell}}{\mathrm{V}_{\mathrm{r}}} \frac{\mathrm{k}_{\mathrm{r}}}{\mathrm{k}_{\ell}}\left(\frac{0.5+\mathrm{e}_{\mathrm{m}} / \mathrm{D}}{0.5-\ell_{\mathrm{m}} / \mathrm{D}}\right)
$$

where the subscripts $\ell$ and $\mathrm{r}$ refer to the elements at the extreme left and right of the plan, respectively, and where $D$ is the distance between these two elements.

\subsection{Torsionally Restrained Systems}

With certain restrictions, to be examined subsequently, the wall arrangement shown in Figure 6 should qualify as a "torsionally restrained" system, when it is subjected to large inelastic translational displacements in the $\mathrm{x}$ or the $\mathrm{y}$ directions. In accord with the postulated design aim, stated in Section 3.1, the

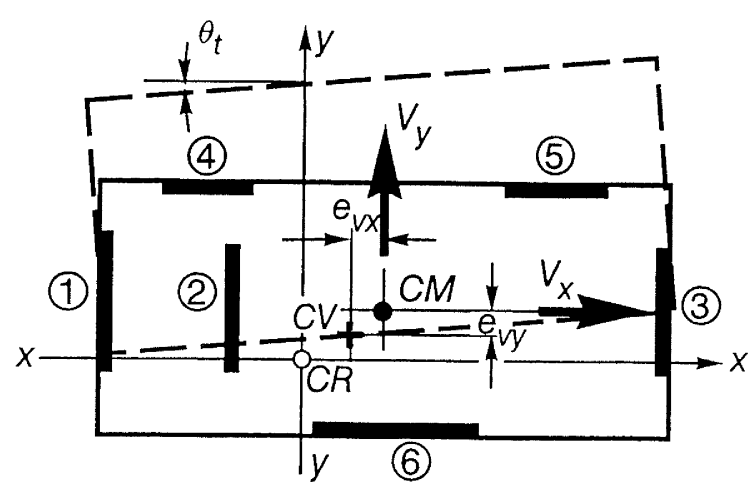

FIGURE 6 A torsionally restrained ductile system.

criterion is simply that walls resisting torsion-induced lateral forces at the ultimate limit state due to the force $V_{y}$, such as Walls (4), (5) and (6), should respond well within the elastic domain when all walls subjected to in-plane forces in the $y$ direction enter the inelastic domain.

Strengths assigned to Walls (1), (2) and (3) will normally be based on an analyses of the elastic system, subjected to the design seismic force, $\mathrm{V}_{\mathrm{y}}$, as outlined in Section 2. Forces assigned to all walls due to code-prescribed additional torsional moments, may be included. When the combined probable strength, $\mathrm{V}_{\mathrm{yp}}$, of these three walls, as constructed, is evaluated, the resultant of the three in-plane forces in the $y$ direction will pass through the point marked $\mathrm{CV}$ in Figure 6 . This point is termed the "centre of resistance" or the "centre of strength" with respect to inelastic translation of the system along the $\mathrm{x}$ or $y$ axis. Because in the presence of torsion, the probable strength of each wall will not be proportional to its stiffness, $\mathrm{CV}$ will not coincide with $\mathrm{CR}$. Hence at this stage, that is after the imposition of the expected significant displacement ductility demand, $\mu_{\Delta}$, a torsional moment, $\mathrm{M}_{\mathrm{t}}=\mathrm{e}_{\mathrm{vx}} \mathrm{V}_{\mathrm{yp}}$, will be developed. In accordance with the assumption of perfect plastic response, after the imposition of significant ductility demands in the y direction, the strength of the Walls (1), (2) and (3) will have been exhausted. Therefore, at this stage they cannot contribute to torsional resistance.

The torsion generated at the ultimate limit state, $\mathrm{e}_{\mathrm{vx}} \mathrm{V}_{\mathrm{yp}}$, will thus need to be resisted by the remaining three walls, ie, (4), (5) and (6). Provided that under the actions of the torsion-induced forces these walls remain elastic, a torsionally restrained ductile system can be relied on. It should be a design aim to conceive such systems.

The magnitude of the associated twist, $\theta_{\mathrm{tu}}$, will be controlled solely by the lateral deflections of the elastic walls subjected to torsion-induced forces in the $\mathrm{x}$ direction. When the deflections of these elastic walls is kept relatively small, which, as a general rule, is easily achieved, the resulting inelastic deflections of Walls (1), (2) and (3) in the y directions should not change the displacement ductility demands imposed on them as significantly as in a torsionally unrestrained system. It will be shown that this feature can be quantified.

A similar approach will enable actions and deformations to be realistically estimated when the earthquake induced translational ductility demand is associated in Figure 6 with $V_{x}$. 


\subsection{Quantifying Torsional Restraint}

As stated, the design aim should be to retain some of the torsional stiffness of the system after the introduction of inelastic translational displacements. The example in Figure 6 illustrated how this could be achieved.

An easily established property, proposed in a recent illuminating study [4] of the torsional provisions in New Zealand [1], is considered appropriate to quantify the degree of torsional restraint in inelastic structural systems. This parameter recognises the reduction of the torsional stiffness, $\mathrm{K}_{\mathrm{t}}$, given by equation (2e), that is, the contribution to twist control of inelastic elements. It is evident that the term referring in this equation to elements which become inelastic should vanish, or reduce significantly to a value that corresponds to the post-yield stiffness of these elements. Residual torsional stiffness is then provided by the elastic elements only. Accordingly the degree of torsional restraint may be quantified by:

$$
\begin{aligned}
& \lambda_{\mathrm{tx}}=\Sigma\left(\mathrm{x}_{\mathrm{i}}^{2} \mathrm{k}_{\mathrm{yi}}\right) / \mathrm{K}_{\mathrm{t}} \\
& \lambda_{\mathrm{ty}}=\Sigma\left(\mathrm{y}_{\mathrm{i}}^{2} \mathrm{k}_{\mathrm{xi}}\right) / \mathrm{K}_{\mathrm{t}}
\end{aligned}
$$

relevant to inelastic translations in the $\mathrm{x}$ and $\mathrm{y}$ directions, respectively.

The values relevant to actions in the $\mathrm{y}$ and $\mathrm{x}$ directions, examined in Figure 3, are $\lambda_{\mathrm{ty}}=0$ and $\lambda_{\mathrm{tx}}=1.0$ respectively. This then defines the absence of torsional restraints of inelastic displacements in the $y$ direction, while maximum torsional restraint is preserved for inelastic actions in the $\mathrm{x}$ direction. It is evident that a base shear, $V_{x}$, could be resisted by the ductile Wall (3) with a very large eccentricity, without Walls (1) and (2) approaching the elastic limit.

When it is necessary to evaluate the angle of twist, $\theta_{t u}$, at the ultimate limit state, the eccentricity to be considered is the distance between $\mathrm{CM}$ and $\mathrm{CV}$, defined as the "strength eccentricity", $e_{v}$. For example, after the development of inelastic translational displacements due to the force $V_{y}$, considered in Figure 6, the angle of twist will be:

$$
\theta_{\mathrm{tu}}=\mathrm{e}_{\mathrm{vx}} \mathrm{V}_{\mathrm{y}} /\left(\lambda_{\mathrm{ty}} \mathrm{K}_{\mathrm{t}}\right)
$$

while for the elastic system:

$$
\theta_{\mathrm{te}}=\mathrm{e}_{\mathrm{rx}} \mathrm{V}_{\mathrm{y}} / \mathrm{K}_{\mathrm{t}}
$$

For this simple assessment of torsional effects on elastic walls of a ductile system, only equilibrium criteria were considered. With the consideration of the stiffnesses of relevant elastic elements, torsion-induced displacements are uniquely defined. Provided that the torsion-generated forces in the $\mathrm{x}$ directions remain well within the domain of elastic response of the affected walls, possible actions due to torsional inertia of the horizontally distributed floor masses, are likely to be insignificant.

When strength has been assigned to each element exactly as derived for the elastic system without consideration of codespecified accidental torsion provisions, $\theta_{\mathrm{tu}}=\theta_{\mathrm{te}}$ and consequently $e_{v}=\lambda_{t} e_{r}$

\subsection{Systems with Large Strength Eccentricities}

To illustrate some features involved when torsional restraint in a system needs to be considered, the extreme wall configurations shown in Figure 7 is used. It is first assumed that the design for ductile seismic response resulted in probable wall strengths, such that the base shear capacity of Wall (1) is three times that of each of the other five small walls. The strength of the small walls is taken as unity. This results in a strength eccentricity of $\mathrm{e}_{\mathrm{vx}}=\mathrm{B}=\mathrm{A} / 4$. Thus the total base shear resistance of the system in each of the two principal directions, $x$ or $y$, is 4 times that of one of the small walls. This structure is shown in Figure $7 \mathrm{a}$.

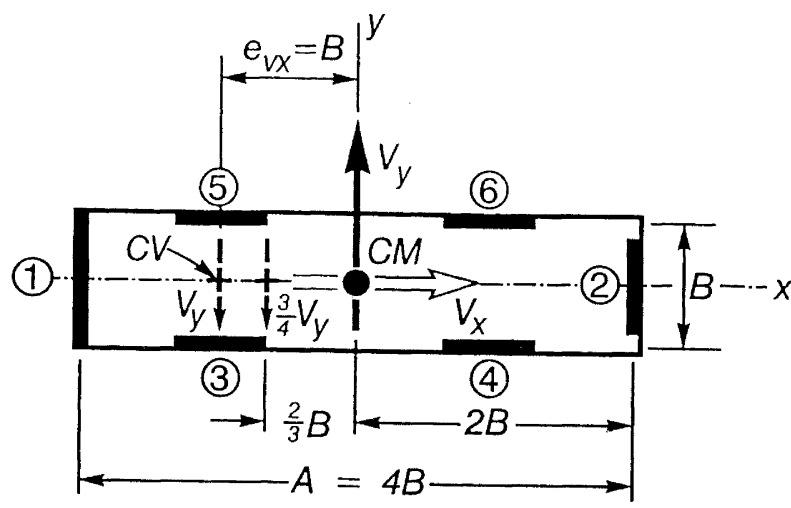

(a) Strength ratio $S_{1} / S_{2}=3$

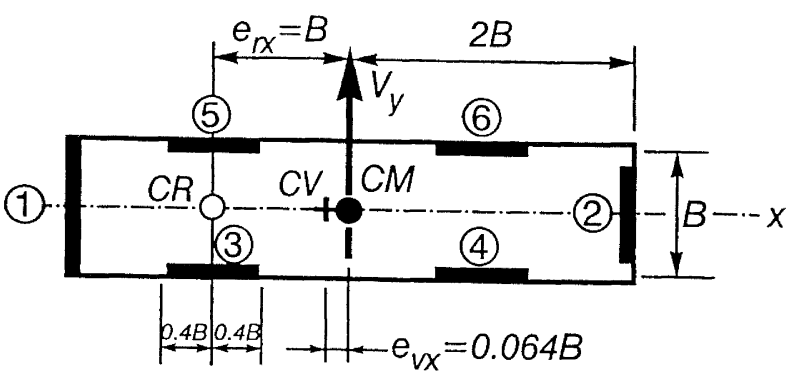

(b) Stiffness ratio $k_{1} / k_{2}=3$ FIGURE 7 A ductile system with inadequate torsional
restraints.

After the imposition of the expected ductility demand in the y direction, the centre of the combined resistances of Walls (1) and (2) would be expected to be located in this example at a distance $e_{v x}=B$ to the left of CM. To resist the resulting torsion, $M_{t}=e_{v x} V_{y}$, would require a force of $V_{y} / 2$ to be developed in each of Walls (3) to (6). Because this force is twice the capacity of the small walls assumed as $V_{y} / 4$, this torsional moment, $\mathrm{M}_{\mathrm{t}}$, cannot be sustained.

However, when Wall (1) remains elastic, while developing strength equal to $\mathrm{V}_{\mathrm{y}} / 2$, rather than $3 \mathrm{~V}_{\mathrm{y}} / 4$, the centre of combined resistances, with total strength reduced to $\mathrm{V}_{\mathrm{ry}}=$ $3 \mathrm{~V}_{\mathrm{y}} / 4$, will be at a distance $2 \mathrm{~B} / 3$ to the left of $\mathrm{CM}$, also shown in Figure 7a. The torsion resulting from this reduced force, $\mathrm{V}_{\mathrm{ry}}$, and reduced strength eccentricity, will develop the full strength, $V_{y} / 4$, of Walls (3) to (6). Thus both, equilibrium and strength criteria, are satisfied.

It must be noted, however, that: 
(i) With all the small walls of the structure shown in Figure 7a entering the inelastic domain of response, the centre of (inelastic) twist moves over to the elastic Wall (1). Also, with $\lambda_{\mathrm{tx}}=0$ (equation (7a)), the system becomes torsionally unrestrained.

(ii) The seismic resistance of the example building in the $y$ direction is reduced to $75 \%$ of that originally intended. The quantified assessment of base shear capacity of a system as a result of torsional demands, is examined in Section 3.10.

(iii) The ductility demand on Wall (2) could increase significantly. The yield displacement of Walls (3) to (6) would commence only after the development of a displacement ductility of more than 4 in Wall (2) with identical stiffness and strength.

(iv) Because of the trends described in (ii) and (iii), the example system does not promise satisfactory seismic performance.

Adequate torsional restraint in and hence satisfactory ductile response of the example structure would be assured, however, for seismic displacements along the $\mathrm{x}$ axis.

\subsection{Systems With Large Stiffness Eccentricities}

To illustrate that a large stiffness ccentricity, defined as $e_{\mathrm{rx}}$, in Figure 1, and derived from analyses for fully elastic response, does not necessarily result in unsatisfactory ductile response, another example will be considered. The structure in plan is the same as that shown in Figure 7a. However, instead of a strength ratio of $3 ; 1$ with respect to the one large and 5 small walls, studied in the previous section, it will be assumed that the same ratio applies now to element stiffnesses.

The structure to be considered is reproduced in Figure $7 \mathrm{~b}$. It is assumed that in accordance with code [1] requirements, an additional accidental eccentricity of $0.1 \mathrm{~A}=0.4 \mathrm{~B}$ is to be considered when designing for a base shear of $V_{y}=V_{E}$. The relevant design eccentricities are shown in Figure $7 \mathrm{~b}$. The twist related restriction of the code [1] for the elastic system, defined by equation (1), is exceeded by $23 \%$. Also, the eccentricity limit shown in Figure 2 is exceeded because $e_{d x}=1.4 \mathrm{~B}=$ $0.35 \mathrm{~A}>0.3 \mathrm{~A}$.

Routine calculations show that, by taking into account also the accidental eccentricities, strengths assigned to Walls (1) and (2) are $0.612 \mathrm{~V}_{\mathrm{E}}$ and $0.574 \mathrm{~V}_{\mathrm{E}}$, respectively, resulting in an increase of the total lateral force resistance to $\mathrm{V}_{\mathrm{y}}=1.186 \mathrm{~V}_{\mathrm{E}}$. The allocation in this example of nearly the same strength to Walls (1) and (2) illuminates the large difference of strength to stiffness ratios, a parameter significantly affecting ductility demands on component elements. The principles of this feature are briefly reviewed in the next section.

After the imposition of inelastic deformations in the y direction, the "centre of resistance" $\mathrm{CV}$, is found to be very close to $\mathrm{CM}$, resulting in a very small eccentricity. This suggests that, in spite of the very large value of $e_{r x}$, some torsional restraint may be provided by elements (3) to (6). This may be demonstrated with the use of the factor of residual torsional restraint, $\lambda_{t}$, given by equation (7). Its value, with respect to the action shown in Figure $7 \mathrm{~b}$, being 0.076 , indicates a dramatic reduction of the full torsional stiffness. However, because of the similar reduction of torsion at the ultimate limit state, the twist is similar to that of the elastic system. The torsion induced forces in Walls (3) to (6) at the ultimate limit state would be less than $20 \%$ of the strength of these walls. The latter is controlled by the base shear $\mathrm{V}_{\mathrm{x}}$. This contrasts with the response of torsionally unrestrained systems, such as shown in Figure 3 , where the development of system displacement ductility was shown to be associated with significant increases of twist.

\subsection{The Role of Strength to Stiffness Ratio}

Because this parameter may elude the attention of some design practitioners, its role is reviewed here. Moreover, the discussion could contribute to a better understanding of the elasto-plastic torsional behaviour of buildings. For this purpose two examples, shown in Figure 8, are used.

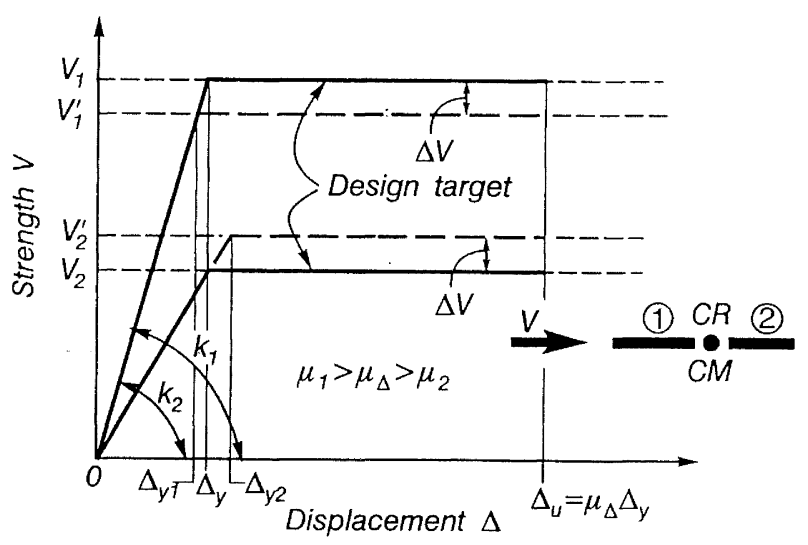

(a) Translation only

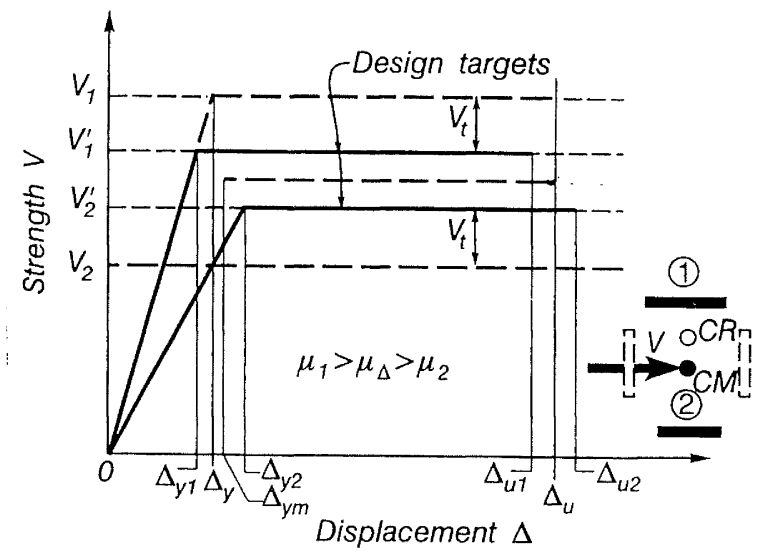

(b) Translation and twist

FIGURE 8 The effects of strength to stiffness ratios on translational and torsional behaviour.

Figure 8a shows the strength relations of two walls with stiffness $k_{1}$ and $k_{2}$, which are subjected to identical ultimate displacements, $\Delta_{\mathrm{u}}$. The analysis of the elastic structure shows that strength should be assigned in proportion of stiffness, so that $\mathrm{V}_{1} / \mathrm{k}_{1}=\mathrm{V}_{2} / \mathrm{k}_{2}$. This results in identical yield displacements, i.e., $\Delta_{\mathrm{y} 1}=\Delta_{\mathrm{y} 2}=\Delta_{\mathrm{y}}$. However, the strength of the walls, as built, $\mathrm{V}_{1}^{\prime}$ and $\mathrm{V}_{2}^{\prime}$, will be inevitably different. This is satisfactory as long as the total resistance, $V_{1}^{\prime}+V_{2}^{\prime}$, is not less than that required, $V_{1}+V_{2}$, and the reduction of strengths of Wall (7) $\Delta \mathrm{V}$, is not excessive. 
The expected system displacement ductility demand is $\mu_{\Delta}=$ $\Delta_{\mathrm{u}} / \Delta_{\mathrm{y}}$. With application of $\mathrm{V}_{1}^{\prime}$ and $\mathrm{V}_{2}^{\prime}$, the yield displacements of the walls, $\Delta_{\mathrm{y} 1}$ and $\Delta_{\mathrm{y} 2}$ will differ from $\Delta_{\mathrm{y}}$. This is also indicated by the fact that the initial identical strength to stiffness ratio has now changed so that $V_{1}^{\prime} / k_{1}<V_{2}^{\prime} / k_{2}$. Hence the ductility demands on the walls will be different, i.e.

and

$$
\begin{aligned}
& \mu_{1}=\frac{\mu_{\Delta}}{1-\Delta V / V_{1}}>\mu_{\Delta} \\
& \mu_{2}=\frac{\mu_{\Delta}}{1+\Delta V / V_{2}}<\mu_{\Delta}
\end{aligned}
$$

The strength reduction on Wall (1) resulted thus in a ductility demand that is in excess of that expected for the system. Because $\Delta \mathrm{V}$ is expected to be relatively small, within certain limits such increase in local ductility demands has been considered acceptable [3]. The magnitude of $\Delta \mathrm{V}$ depends largely on the designer's choice.

Figure $8 \mathrm{~b}$ illustrates the same walls in a different role. The analysis of the elastic system shows that the torsion generated force, $V_{t}$, in the two walls, which may be quite significant, inevitably leads to a situation whereby $V_{1}^{\prime} / k_{1}<V_{2}^{\prime} / k_{2}$. Therefore the difference in ductility demands imposed on the walls by system translation, i.e., translation of $\mathrm{CM}$, will be significant. The similarity of the response of the walls illustrated in Figures $8 \mathrm{a}$ and $8 \mathrm{~b}$ are evident. However, there is another feature which needs also to be considered. This is the definition of the yield displacement, $\Delta_{y}$, applicable to the system. As stated earlier this should be taken at CM. For the example in Figure $8 \mathrm{~b} \Delta_{\mathrm{y}}=0.5\left(\Delta_{\mathrm{y} 1}+\Delta_{\mathrm{y} 2}\right)$. Therefore ductility demands for a given system ductility, $\mu_{\Delta}=\Delta_{\mathrm{u}} / \Delta_{\mathrm{y}}$, will be different for each wall. That for the stiffer Wall (1) may be the critical. It may be readily shown that for the central position of $\mathrm{CM}$, as shown in Figure $8 \mathrm{~b}$,

$$
\mu_{1}=\frac{1}{2}\left[1+\frac{\left(V_{2}+V_{t}\right) k_{1}}{\left(V_{1}-V_{t}\right) k_{2}}\right]\left(\mu_{\Delta}-1\right)+1
$$

For a symmetrical structure, when $\mathrm{k}_{1}=\mathrm{k}_{2}$ and therefore $\mathrm{V}_{\mathrm{t}}=$ 0 and $V_{1}^{\prime}=V_{2}^{\prime}$, as expected, $\mu_{1}=\mu_{2}=\mu_{\Delta}$. The magnitude of $V_{t}$, shown in Figure $8 \mathrm{~b}$, is not the designers choice. It is controlled by eccentricities.

\subsection{A Global Assessment of the Torsional Response of Ductile Systems}

While preparing this review, the author was made aware of a recent important study contributing to the understanding of the inelastic seismic behaviour of asymmetric-plan buildings [7]. It confirmed the findings resulting from the previous simple examples presented here. It considered a wide range of the two principal variables, element stiffness and element strength. It postulated a conceptual framework enabling a qualitative assessment of the contribution to inelastic response of the fundamental mechanisms, i.e., those associated with translational and torsional displacements, to be made.

This innovative study presented a simple and transparent interpretation of the interaction of translational and torsional mechanisms at the ultimate limit state. It is in the form of an interaction surface for "base shear and torque", abbreviated subsequently as BST, describing the combination of statically applied forces that leads to the formation of a fully plastic mechanism. The technique is similar to that used in the construction of the interaction at the ultimate limit state of axial load and moment applied to sections of reinforced concrete columns. Any point within the boundaries signifies elastic response. Those at the boundary quantify the situation at the plastic state. Because of its importance, in terms of understanding of structural behaviour, the concept is illustrated with relevance to two of the example structures used here.

Figure $3 \mathrm{~b}$ shows the interaction relationship between the base shear, $V_{y}$, and the possible torsional moment, $M_{t}$, for the previously studied example in Figure 3a. The horizontal axis plots the base shear strength normalized in terms of the required design strength $\mathrm{V}_{\mathrm{E}}$. Hence point (1) shows $\mathrm{V}_{\mathrm{y}} / \mathrm{V}_{\mathrm{E}}=1.25$ when $\mathrm{M}_{\mathrm{t}}=0$. Under pure torsional response the ultimate torque developed will be $\mathrm{M}_{\mathrm{t}, \max }=\left(0.5 \times 1.25 \mathrm{~V}_{\mathrm{E}}\right) \times 0.8 \mathrm{~A}=0.5 \mathrm{AV} \mathrm{E}$. This is plotted at point (2). Because only equilibrium criteria are involved, the relationships shown in Fig. $3 \mathrm{~b}$ are linear. It is thus evident that, should for any reason an eccentricity with respect to the assumed location of the $\mathrm{CM}$ arise, resulting in torsion, the translational strength of the system in the y direction will rapidly reduce.

A similar consideration of base shear action in the $\mathrm{x}$ direction, $\mathrm{V}_{\mathrm{x}}$, reveals that the three walls do not interact. Therefore, as the BST relationship in Figure 3c shows, the full base shear and large torsional strength can be developed simultaneously at all stages of the response. This illustrates the very beneficial effect of full torsional restraint. While some torsion will be inevitably induced during a seismic event, it is evident that with the strength ratio $V_{3} / V_{1}=V_{3} / V_{2}$, implied by the dimensions seen in Figure $3 \mathrm{a}$, it could never produce a torque approaching the full torsional strength of the system. Hence under the action of $\mathrm{V}_{\mathrm{x}}$, Walls (1) and (2) will always respond within elastic limits and the ductility demand on Wall (3) will hardly be affected by twist.

\section{DUCTILE SYSTEMS SUBJECTED TO EARTHQUAKE-INDUCED DISPLACEMENTS IN DIFFERENT DIRECTIONS}

Design for seismic resistance implies that the base shear, $V_{E}$, evaluated from code-prescribed procedures, should be able to be sustained irrespective of the direction of the earthquake attack. This is implied in Figure 1 . Corresponding inelastic displacements may force all walls, irrespective of their orientation, into the post-elastic domain. Thereby the strongly advocated beneficial contribution of elastic walls to the control of twist, may be reduced or even lost. This necessitates a reexamination of ductile response under skew earthquake attacks. Figure 9 shows a model of an example structure, symmetrical with respect to the s-s axis, used to highlight the relevant issues.

The structure is to sustain at the ultimate limit state a base shear, $V_{E}$, associated with an expected system displacement ductility demand of $\mu_{\Delta}=5$, at CM. Individual walls are assumed to have been detailed to possess a comparable ductility capacity. The wall dimensions are such that the relative stiffnesses of the long and short walls are 0.7 and 0.3 , respectively. These properties result in the location of $\mathrm{CR}$, as shown in Figure 9a.

In determining the strength of each wall, traditional code provisions [1] were used, whereby an "accidental eccentricity" of $\pm 0.1 \mathrm{~A}$, in addition to the "stiffness eccentricity" $(0.2 \mathrm{~A})$, was considered. Accordingly the required strength of Wall (1) and Wall (3) is $0.65 \mathrm{~V}_{\mathrm{E}}$ and $0.45 \mathrm{~V}_{\mathrm{E}}$, respectively. This resulted 


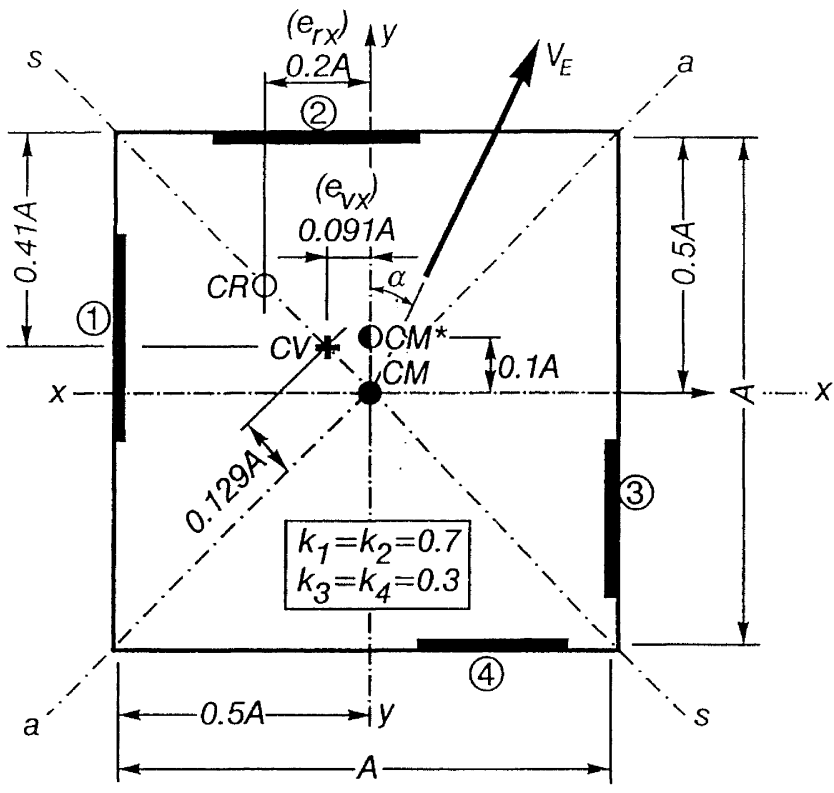

(a) Plan

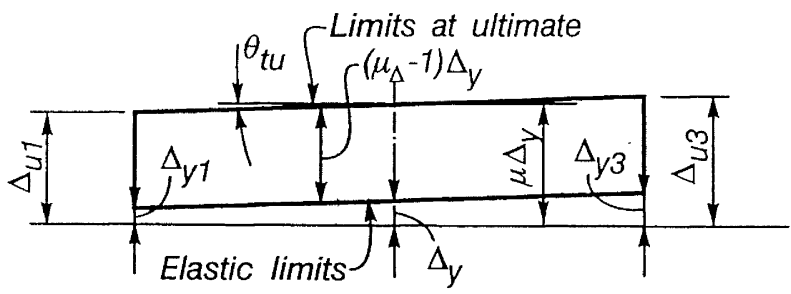

(b) Deformations when $\alpha=0$

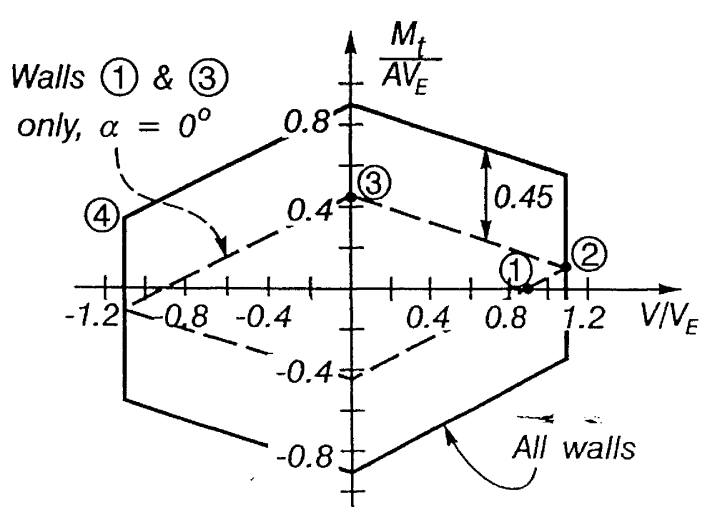

(c) Base shear-torque surface

\section{FIGURE 9 A wall system under skew earthquake attack.}

in $10 \%$ increase of the total lateral force resistance to $1.1 \mathrm{~V}_{\mathrm{E}}$ Hence it can be expected that the displacement ductility demand on the system in the $\mathrm{x}$ or $\mathrm{y}$ directions will correspondingly reduce to $\mu_{\Delta}=4.55$.

\subsection{Earthquake Attack Along the y Axis $(\alpha=0)$}

When under the action of $1.1 \mathrm{~V}_{\mathrm{E}}$ with $\alpha=0$, Walls (1) and (3) develop their full strength, the resultant of the corresponding forces will pass through $\mathrm{CV}$, located as shown in Figure 9a. The associated torsion $\mathrm{M}_{\mathrm{t}}=0.091 \mathrm{~A} \times 1.1 \mathrm{~V}_{\mathrm{E}}=0.1 \mathrm{AV} \mathrm{V}_{\mathrm{E}}$ and the corresponding forces in Walls (2) and (4), $0.1 \mathrm{~V}_{\mathrm{E}}$, are thus uniquely defined. In this example the torsion-generated forces in Walls (2) and (4) correspond to only $15 \%$ and $22 \%$ of their strength, 0.65 and $0.45 \mathrm{~V}_{\mathrm{E}}$, respectively. Hence their elastic response is assured. An evaluation of equation (7), with $\lambda_{t}=$ 0.5 , also indicates considerable torsional restraint. The deformations in these two walls determine the angle of twist, $\theta_{\mathrm{tu}}$, shown in Figure $9 \mathrm{~b}$. Generally the angle of twist at the ultimate limit state, $\theta_{\mathrm{tu}}$, is the same as that at the onset of yielding of the translatory elements, $\theta_{\mathrm{te}}$, as indicated by equations (8a) and (8b).

The yield displacement of the system, $\Delta_{y}$, at CM, may in this case be taken as the average of the yield displacements of Walls (1) and (3), as seen in Figure 9b. The magnitude of the total expected ultimate translational displacement along the $\mathrm{y}$ axis, $\Delta_{\mathrm{u}}=4.55 \Delta_{\mathrm{y}}$, may thus be estimated. As Figure $9 \mathrm{~b}$ shows, twist will in this case only slightly alter the ultimate displacements which Wall (1) or (3) may be subjected to. Evaluation of the corresponding ductility demands on these two walls show that $\mu_{1}=5.63>5.00$ and that $\mu_{3}=3.84<5.00$. The same response is relevant when displacements occur along the $\mathrm{x}-\mathrm{x}$ axis $\left(\alpha=90^{\circ}\right)$. With $\mathrm{V}_{1}=0.65 \mathrm{~V}_{\mathrm{E}}$ and $\mathrm{V}_{3}=0.45$ $\mathrm{V}_{\mathrm{E}}$ equation (10) yields

$$
\mu_{1}=\frac{1}{2}\left(1+\frac{0.45}{0.65} \times \frac{0.7}{0.3}\right)(4.55-1)+1=5.64
$$

Example A, presented in the Appendix, demonstrates that, inspite of the significant stiffness eccentricity $(0.2 \mathrm{~A})$, a system displacement capacity of $\mu_{\Delta}=5$ could be relied on without an increase of the lateral force resistance of the stucture that would result from code requirements[1] for "accidental" eccentricity.

\subsection{The Base Shear-Torque Surface $(\alpha=0)$}

To illuminate the interaction of translational and torsional response of the system at the ultimate limit state, the base sheartorque (BST) surface [7], applicable to the example or a similar structure, is presented in Figure 9c. The four quadrants show the four possible combinations of shear and torque with $\pm V_{E}$ and $\pm \mathrm{M}_{\mathrm{t}}$ when $\alpha=0$

First a structure comprising Walls (1) and (3) only, but with strengths as determined above, will be considered for actions relevant to the first (upper right) quadrant. A force $V_{y}$ without a torsion can only be sustained if there is no eccentricity. This leads to a force equal to twice the strength, $\mathrm{V}_{3}$, of the weaker of the two walls, i.e., $2 \times 0.45 \mathrm{~V}_{\mathrm{E}}$. This is point (1) in Figure 9c. When the full translational strength of the structure, $V_{y}=$ $1.1 \mathrm{~V}_{\mathrm{E}}$, is developed, with an eccentricity of $\mathrm{e}_{\mathrm{vx}}=0.091 \mathrm{~A}$ (Figure 9a) and the corresponding torque, $0.1 \mathrm{AV}_{\mathrm{E}}$, point (2) is obtained. The full torsional strength of the two walls is again controlled by the strength of Wall (3), $0.45 \mathrm{~V}_{\mathrm{E}}$. Hence the maximum torque is $0.45 \mathrm{AV}_{\mathrm{E}}$, as recorded at point (3). Note that at this stage no base shear in the $y$ direction can be maintained. The similarity of the surface shown by the dashed lines in Figure 9c and that in Figure $3 \mathrm{~b}$ is evident. Because of the lack of torsional restraint in the absence of Walls (2) and (4), with the application of a torque in excess of that indicated at point (2), translational resistance is rapidly reducing.

The role of Walls (2) and (4) during the translational response in the y direction of the full structure, shown in Figure 9a, is to provide torsional restraint. The maximum torque that can be sustained by these two walls is the same as that of the other two walls. The resulting BST surface is thus the same as shown by the dashed lines, but extended by the torsional capacity, $0.45 \mathrm{AV}_{\mathrm{E}}$, of the walls carrying forces in the $\mathrm{x}$ direction. It is seen that for actions represented in the first quadrant, an eccentricity of $\mathrm{e}_{\mathrm{rx}}=(0.45+0.10) \mathrm{AV}_{\mathrm{E}} / 1.1 \mathrm{~V}_{\mathrm{E}}=0.5 \mathrm{~A}$ would 


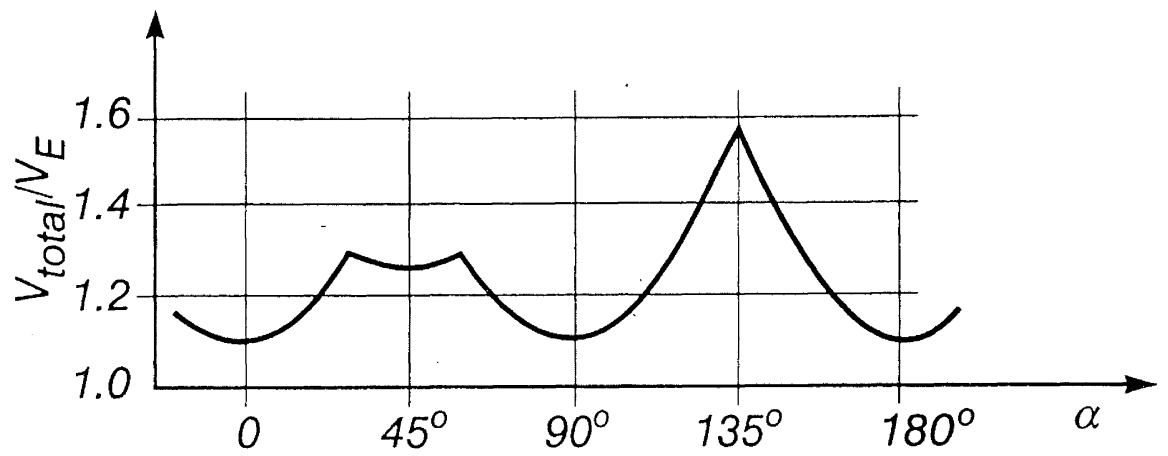

(a). Total strength

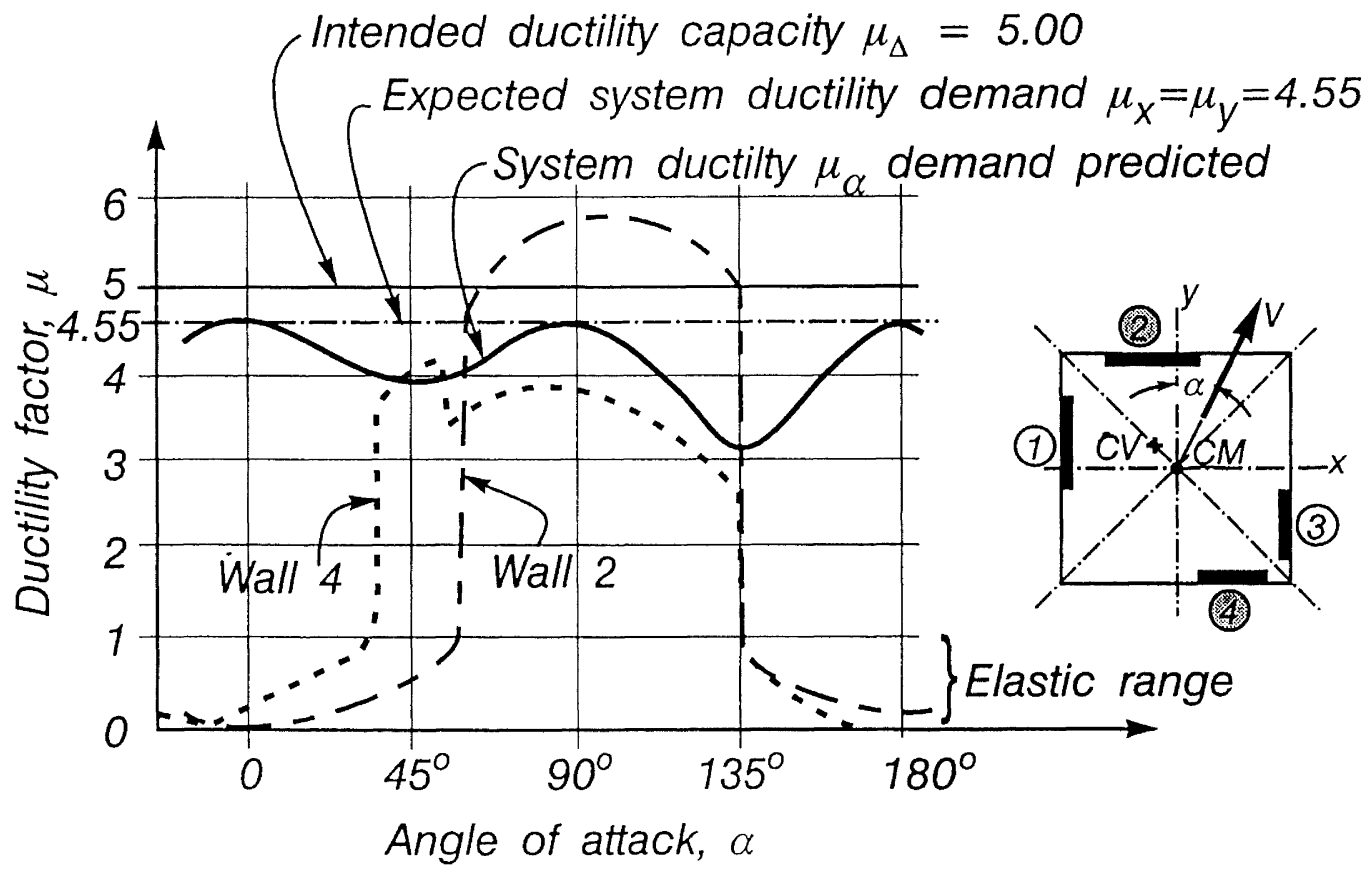

(b) Ductility

FIGURE 10 Variation of strength and expected maximum ductility demands with the angle of seismic, attack.

need to develop before torsion would reduce the full base shear strength of the system in the y direction. Because this is not possible, Walls (2) and (4) will remain elastic and will ensure that, while $\alpha=0$, twist will not significantly affect the deformations of and hence ductility demands on the inelastic walls. However, for a reversal of the base shear $\left(-V_{E}\right)$, a torque of only $(0.45-0.10) \mathrm{AV}_{\mathrm{E}}=0.35 \mathrm{AV}_{\mathrm{E}}$ could be developed $\left(\mathrm{e}_{\mathrm{rx}}=0.32 \mathrm{~A}\right)$ before the base shear capacity would reduce. This is point (4) in Figure 3c.

\subsection{Diagonal Earthquake Attack Along the s-s Axis $\left(\alpha=135^{\circ}\right)$}

As $\mathrm{CV}$ and $\mathrm{CM}$ lie on this axis, predictable twist other than that due to torsional motions of the mass, does not arise. The combined strength of all four walls with respect to this axis is now $1.1 \sqrt{ } 2 \mathrm{~V}_{\mathrm{E}}=1,56 \mathrm{~V}_{\mathrm{E}}$ (Figure 10a). Hence the associated ductility demand can be expected to reduce to $\mu=5 / 1.56=$ 3.2 (Figure 10b). However, with all walls in the inelastic domain, ie, $\lambda_{t}=0$, theoretically there is no torsional restraint. 


\subsection{Diagonal Earthquake Attack Along the a-a Axis $\left(\alpha=45^{\circ}\right)$}

With four plastified walls without any post-yield stiffness, a torsional moment that would result from a strength eccentricity of $0.129 \mathrm{~A}$, shown in Figure 9a, cannot be resisted. Hence the "centre of resistance", $\mathrm{CV}$, of the walls must "move" so as to coincide with $\mathrm{CM}$. This requires that the forces developed in Walls (1) and (2) be equal to those at the other corner of the building. Therefore, Walls (1) and (2) will remain in the elastic domain. The combined strength with respect to the a-a axis reduces therefore to $4 \times 0.45 \mathrm{~V}_{\mathrm{E}} / \sqrt{2}=1.27 \mathrm{~V}_{\mathrm{E}}$, suggesting a maximum ductility demand in this direction of $\mu=3.94$ (Figures 10a and 10b).

$\mathrm{CV}$ for this example needs redefinitions. In this case it is the centre of resistance of the system in which some elements can not develop their full strength.

According to equations (7a) and (7b) $\lambda_{t x}=\lambda_{t y}=0$, and hence for this direction of the seismic attack, the ductile system has become torsionally unrestrained. The displacements of the elastic walls at the upper left hand corner of the plan, and that at the centre of the mass, $\Delta_{\mathrm{m}}=3.94 \Delta_{\mathrm{y}}$, are known. The reference yield displacement $\Delta_{\mathrm{y}}$ has been derived from the computed translation of $\mathrm{CM}$ in the $\mathrm{x}$ or $\mathrm{y}$ directions, as shown in Figure 9b. Hence the corresponding displacement at the corner opposite to the centre of inelastic twist can be determined. As Figure 11c suggests, this leads to a very significant increase of the twist of the system, even though the resulting ductility imposed on Walls (3) and (4) corresponds to only $\mu_{3}=\mu_{4}=4.52<5.0$. While structural integrity would not be jeopardised, the resulting absolute displacements $\left(\Delta_{\mathrm{u}}=5.6 \Delta_{\mathrm{y}}\right)$ and interstorey drifts at that corner along the $\mathrm{x}$ or $y$ directions must be checked, as it may be excessive.

\subsection{A Comparison of the Features of Skew Seismic Response}

A number of features of the structural response of the system shown in Figure 9a, evaluated as a function of the direction, $\alpha$, of the base shear are summarised in Figures 10 and 11 . They represent trends that can be expected under skew seismic attack, possibly warranting attention of the designer.

- As a result of enhancements of the total lateral strengths in different directions of imposed inelastic displacements, shown in Figure 10a, the anticipated system ductility demands, along the diagonal axes of the plan, are less then those relevant to the $\mathrm{x}$ and $\mathrm{y}$ axes. They are shown as $\mu_{\alpha}$ by the full line curve in Figure $10 \mathrm{~b}$.

- Ductility demands on the large walls are slightly exceeding the assumed capacity $\mu_{\Delta}=5.0$ when inelastic displacements occur along the $\mathrm{x}$ or $\mathrm{y}$ axes. This results from the fact that the yield displacement, $\Delta_{y}$, determined at $\mathrm{CM}$, is larger than that of Wall (2), $\Delta_{\mathrm{y} 2}$, and the influence of the strength to stiffness ratios, as explained in Section 3.9 .

- Irrespective of the direction of attack, ductility demands on the small walls, such as Wall (4), remain sub-critical (Figure 10b).

- Under earthquake attack along the a-a axis, when $\alpha=45^{\circ}$, a dramatic increase of twist, $\theta_{\mathrm{t}}$, as shown in Figure 11 may occur. The sudden increase of twist or ductility demand on Wall (4), shown in Figures 11a and 10b, results from the analysis based on perfect elastic-plastic response. With a small amount of post yield stiffness, as shown in Figure $11 \mathrm{a}$, the value of the maximum twist is reduced.

The angle of attack, $\alpha$, used in Figures 10 and 11 is that of the direction of the base shear $\mathrm{V}$ for which the analyses were carried out. With the exception of base shear acting along the principal axes, that is, when $\alpha=0,45^{\circ}, 90^{\circ}$ and $135^{\circ}$, the ensuing displacement of the $\mathrm{CM}$ will not coincide with that of the base shear. For the sake of illustrating this interesting feature of behaviour, Figure 12 is presented. It compares the respective angles at the onset of yielding and at the ultimate limit state. The abrupt changes at certain angles of the base shear occur when inelastic wall deformation sets in, based on perfect elastic-plastic modelling.

- With the exception of an attack along the axis of symmetry, conditions for a different position of the "centre of mass", such as at $\mathrm{CM}^{*}$ seen in Figure 9a, would be less critical. However, when inelastic displacements occur at $\alpha=135^{\circ}$, some increase of the in-plane forces in Walls (2) and (3) and corresponding decrease in Walls (1) and (4), in comparison with those generated with the absence of eccentricity, would have to occur. With reliance on some post-yield stiffness at the prevailing relatively low ductility demand, leading to a residual torsional stiffness of the order of $0.05 \mathrm{~K}_{\mathrm{t}}$, this could be expected to take place at the expense of some moderate (clockwise) twist.

\section{DUCTILE FRAME SYSTEMS}

Considerations of torsional behaviour, discussed so far, are strictly applicable to one storey structures (Figure 1). When prismatic walls, with plastic hinges developing at the base only, provide the total lateral force resistance, the simulation with one storey models is reasonable. With frames greater uncertainties are involved.

The assessment of torsional effects on the ductility demands imposed by the design earthquake on members of frames, which provide the entire lateral force resistance of a building, may be approximated using the principles outlined in the previous sections. The relevant properties of the walls, which were shown in the previous examples, are simply to be replaced by the equivalent properties of frame bents located on the corresponding grid lines. The essential differences in comparison with the response of structural walls, which need to be considered, are:

- Because ductility may develop in any of as well as several of the storeys, the investigation, if required at all, needs to be carried for one storey at a time. In practice this will probably reduce the study to that of a few storeys, if any, in which the designer will suspect that torsional effects on inelastic response may become significant.

- The combined "centre of resistance", CV, of all bents, in terms of the storey shear sustained by all columns, may be readily evaluated. As Figures 13 and 14 illustrate, two cases need be distinguished.

Figure 13 models a familiar (preferred) ductile mechanism, based on strong columns and weak ductile beams. With the identified positions of all the plastic beam hinges, the moments at the node points, that is, the centre lines of the columns, can be readily evaluated. These beam moments 


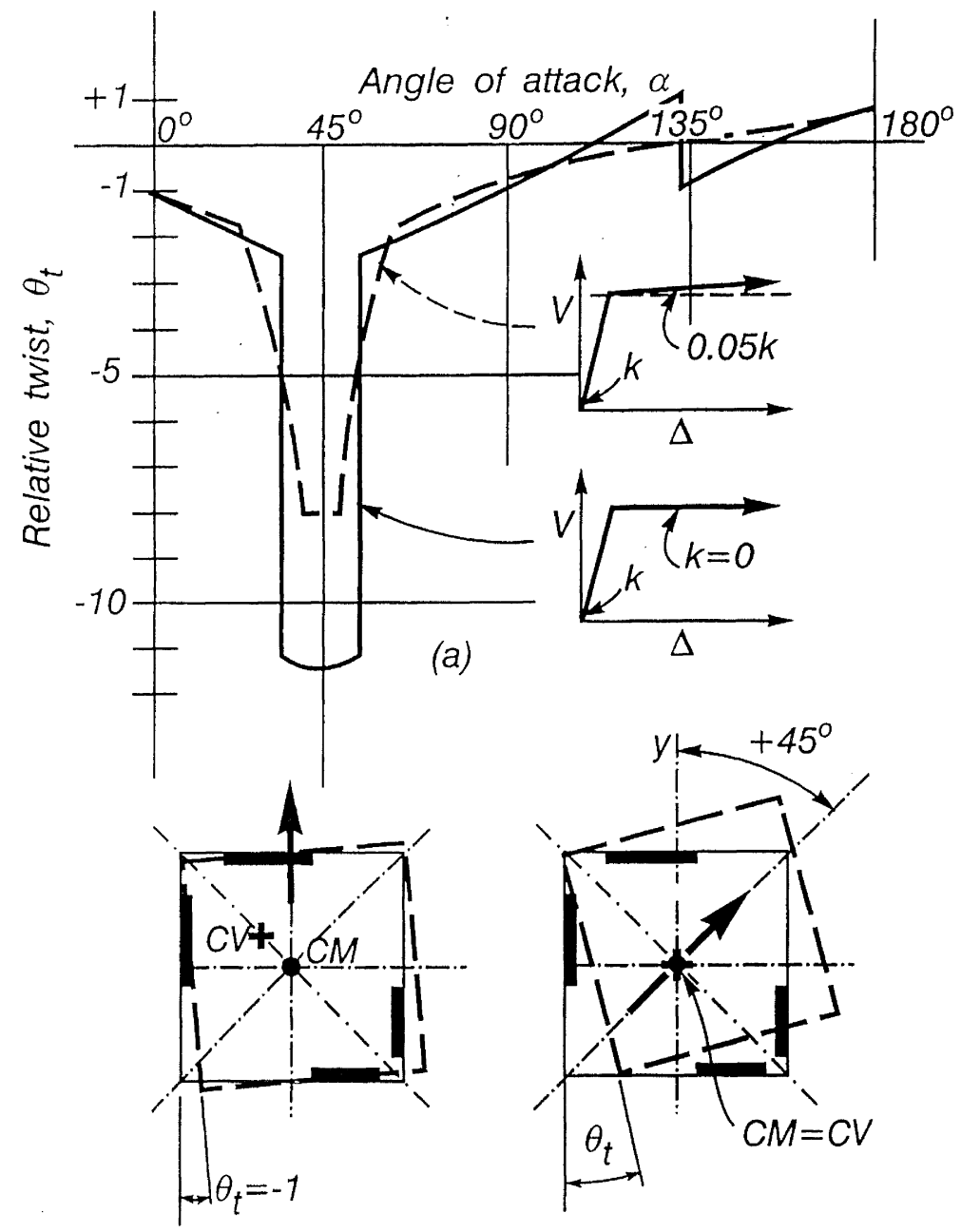

(b)

(c)

FIGURE 11 Variation of relative twist with the angle of the seismic attack.

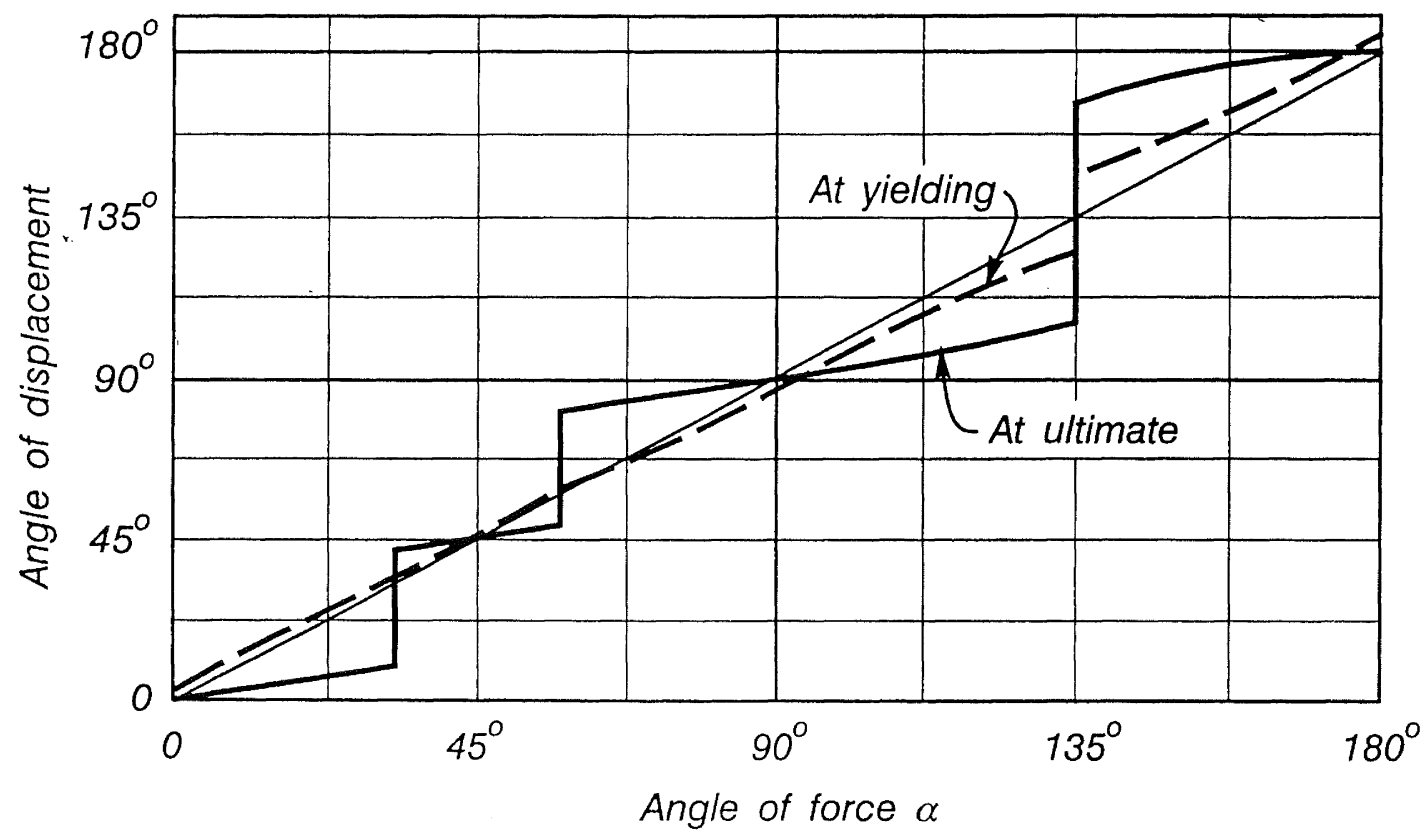

FIGURE 12 The relationship between the angle of the force and the angle of displacement during skew earthquake attacks. 


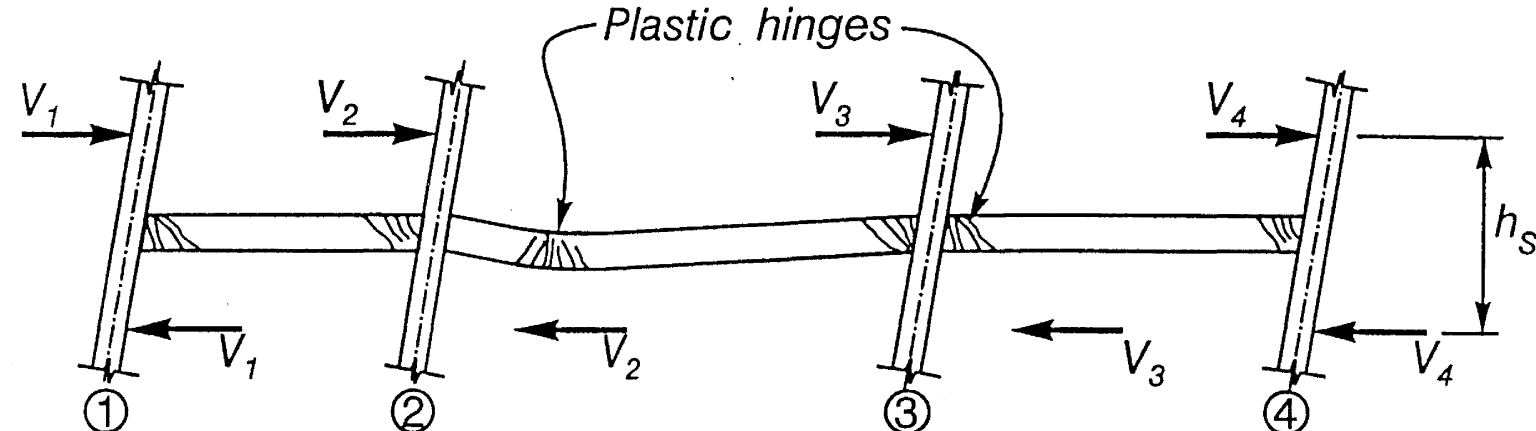

(a) Beam mechanism

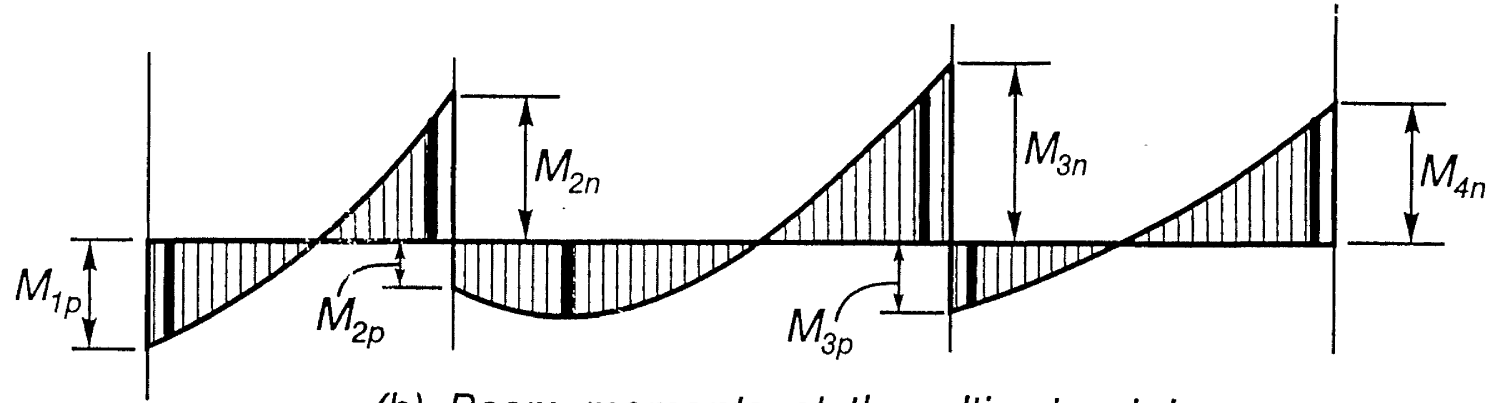

(b) Beam moments at the ultimate state

FIGURE 13 Storey shear forces across a bent associated with a beam sway mechanism.

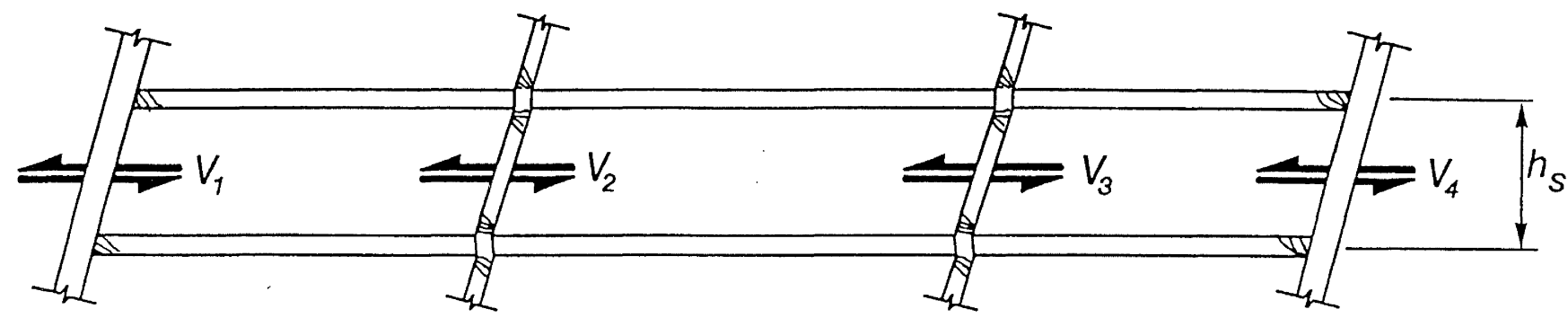

(1) (2)

(a) Mixed mechanism

(4)

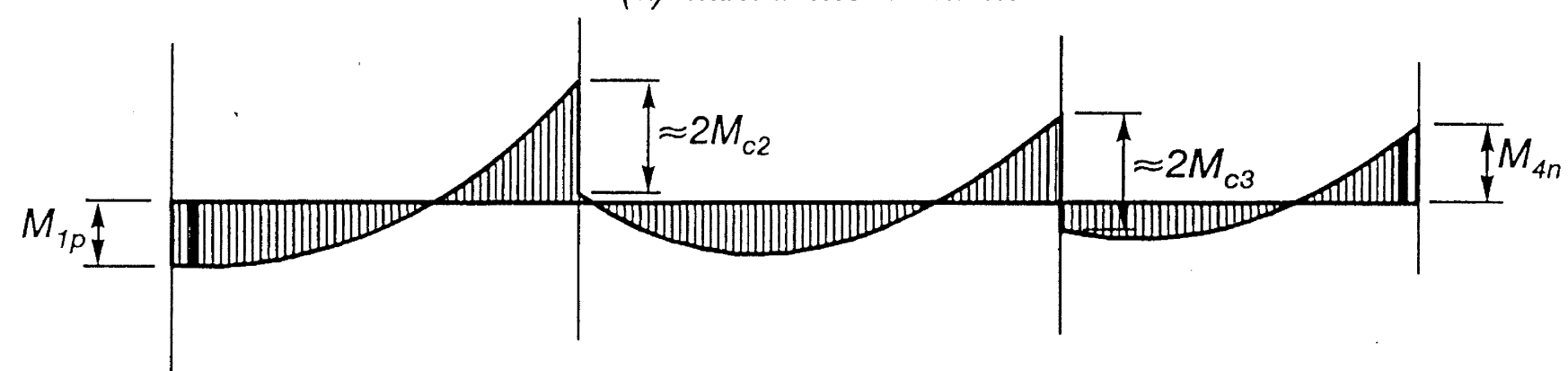

(b) Beam moments at the ultimate state 
may be based on the overstrength of the plastic hinges, values of which, being essential parts of the design calculations, are available. They were required for the design for beam shear strength, that of the beam-column joints and the columns [2]. However, when convenient, for the purpose of establishing the location of $\mathrm{CV}$, probable strengths may also be used. The storey shear force, $\mathrm{V}_{\mathrm{sj}}$, generated in one bent at the ultimate limit state is:

$$
\mathrm{V}_{\mathrm{sj}}=\Sigma \mathrm{V}_{\mathrm{i}}=\left(\Sigma \mathrm{M}_{\mathrm{ip}}+\Sigma \mathrm{M}_{\mathrm{in}}\right) \mathrm{h}_{\mathrm{s}}
$$

where $h_{s}$ is the storey height and the subscripts $p$ and $n$ refer to column centre line moments developing due to positive and negative beam moments, respectively.

Figure 14 shows the relevant information required to evaluate the storey shear capacity of a bent with a mixed mechanism, which relies predominantly on admissible plastic hinges [2,3] formed at both ends of interior columns. As these mechanisms usually occur in frames with limited ductility capacity, this fact should be taken into account when assessing the possible adverse effects of excessive twist. This is particularly important when the structure is designed to meet limited ductility demands because the presence of significant horizontal irregularities.

- The centre of the combined resistance of all bents, CV is a point at which the requirement of:

$$
\Sigma \mathrm{V}_{\mathrm{sj}} \mathrm{d}_{\mathrm{j}}=0
$$

is satisfied, where $d_{j}$ is the perpendicular distance in the horizontal plane from $\mathrm{CV}$ of the bent located at $\mathrm{j}$ (Figure $15)$.

- For imposed inelastic deformations along the reference axes $\mathrm{x}$ and $\mathrm{y}$ of ductile multi-bay two-way frame systems, such as shown in Figure 15, there should always be adequate residual torsional stiffness to limit twist generated at the ultimate limit state. It will be recalled that the torque to be considered for twist control results at this stage from the eccentricities $e_{v y}$ and $e_{v x}$, respectively (Figure 15a). Therefore, contrary to the predictions implied by current code requirements [1], lack of torsional restraint is not likely to arise ever in two-way framed buildings, such as illustrated in Figure 15a.

- The enigma of skew earthquake attack remains, and is likely to be the only torsional issue to be addressed in the design of framed buildings. Figure 15 should assist in identifying relevant factors.

Figure $15 b$ illustrates the situation when a skew displacement, $\Delta_{\mathrm{mu}}$, mobilizes the probable strength of all bents in both the $\mathrm{x}$ and $y$ directions. The displacement induced force $V_{u}^{*}$, causing some twist, $\theta_{t}^{*}$, would need to pass through $\mathrm{CV}$. This, however, is not possible because, with all bents becoming fully plastic, the torque implied in this figure cannot be resisted. The force $\mathrm{V}_{\mathrm{u}}^{*}$ is the theoretical maximum that could be developed in the system with given strengths of the bents.

Figure $15 \mathrm{c}$ shows the corrective displacements and twist, $\Delta \theta_{\mathfrak{t}}^{*}$, which the system must undergo to enable the ultimate skew storey shear force, $V_{u}$, to be sustained in equilibrium. It suggests that as a result of unrestricted twist, the storey shear forces in some bents, such as 1-4 and I-IV, must reduce below the intensity of probable strength, while those at the opposite edges maintain their full strength. This will enable the ultimate

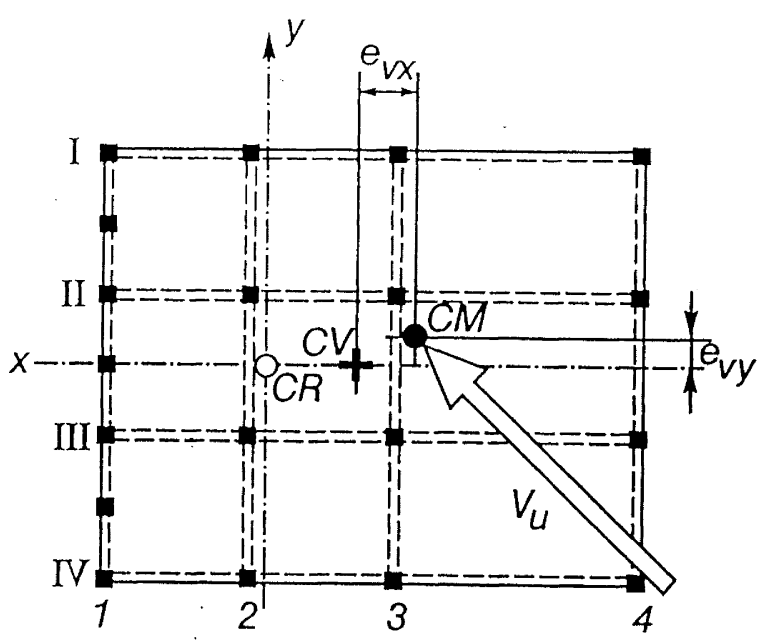

(a) Plan

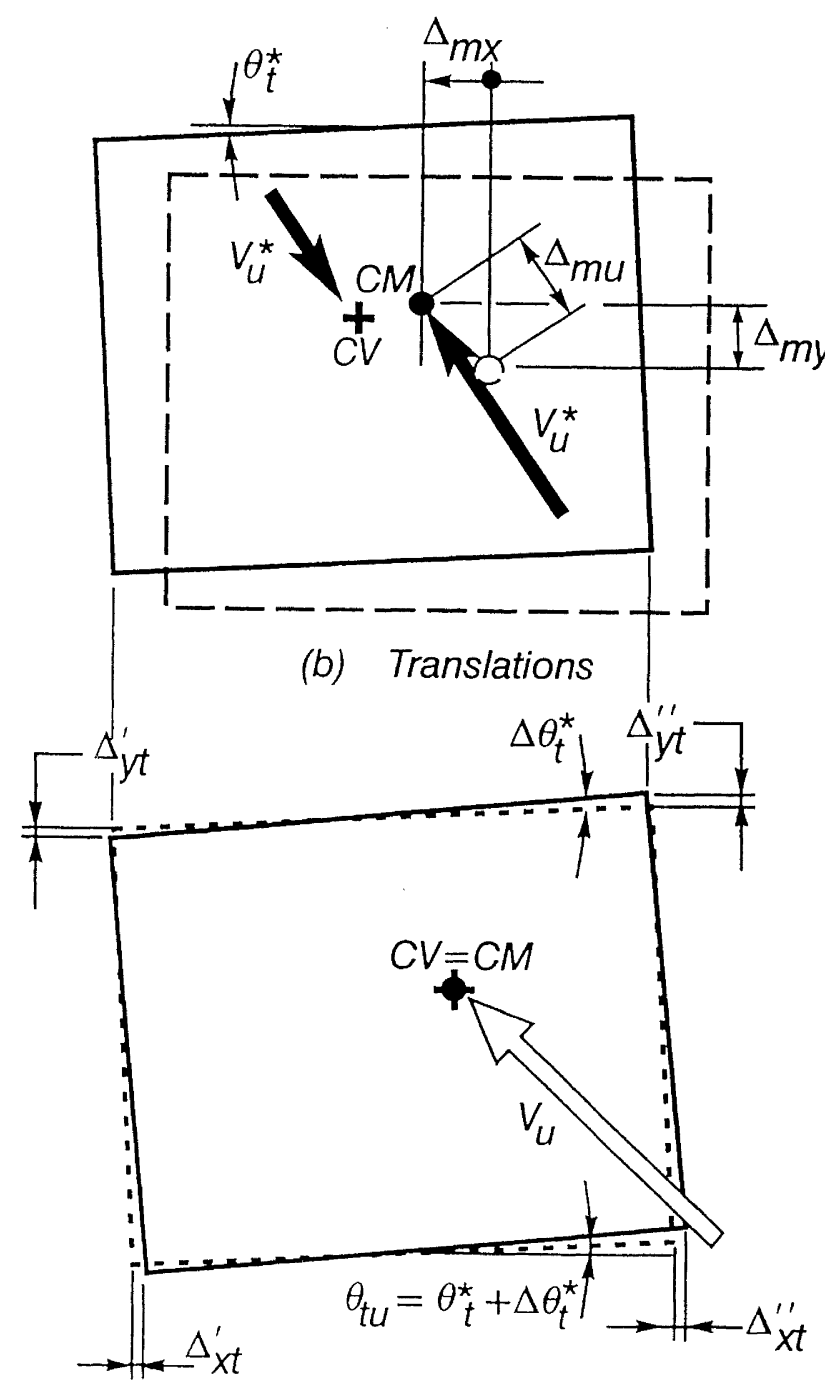

(c) Twist

FIGURE 15 Relative displacements due to skew earthquake attack in a structure with ductile frames. 
storey shear associated with this skew displacement, $\mathrm{V}_{\mathrm{u}}<\mathrm{V}_{\mathrm{u}}^{*}$, to be developed. The prerequisite which the structure will satisfy, is that $\mathrm{CV}$ and $\mathrm{CM}$ coincide.

Reference (7) describes also the construction and interpretation of BST surfaces for one storey structures with ductile frames only.

The greater fraction of the lateral force resistance, $V_{u}$, is assigned to perimeter frames, the larger the residual torsional stiffness - a very desirable structural feature. If a check on possibly excessive ductility demands is to be carried out, the displacements and forces on the perimeter only should need to be considered, as suggested in Section 6 .

Beam mechanisms, such as shown in Figure 13, can be sustained in orthogonally placed frames (Figure 15a) only when the columns are designed to absorb within the elastic domain the maximum moment inputs from all beams supported. This is achieved with the application of the relevant recommendations of capacity design procedures [3]. Accordingly the maximum total strength with respect to base shear will be developed along diagonals of the plan.

With the mechanism depicted in Figure 14, the strength of the columns with respect to diagonal displacements will be approximately $90 \%$ of that along the principal axes. Base strength increase under diagonal seismic attack would then result only from frames, typically at the perimeter of the plan, where columns have been designed to remain elastic.

\section{DEVELOPMENT OF A DESIGN APPROACH}

The examples shown demonstrated that displacement ductility demands imposed on various elements are influenced by the angle of twist $\theta_{\mathrm{t}}$. At the ultimate limit state this is controlled by the torsional restraint offered by the elastic elements, conveniently quantified by the parameter $\lambda_{t}$ and the strength eccentricities, $\mathrm{e}_{\mathrm{vx}}$ and $\mathrm{e}_{\mathrm{vy}}$.

\subsection{Torsionally Restrained Systems $\left(\lambda_{t} \geq 0\right)$}

For convenience, the steps leading to the development of simple design recommendations are discussed in relation to a structure similar to that shown in Figure 9a. In this system strength in Walls (1) and (3) in the y direction have been assigned "exactly" as derived from an elastic analysis without consideration of code-recommended accidental eccentricity.

Once the yield displacements, $\Delta_{\mathrm{y} 1}$ and $\Delta_{\mathrm{y} 3}$, have been quantified, as shown in Figure $9 \mathrm{~b}$, the angle of twist $\theta_{\mathrm{t}}$ is also given: However, if necessary, this can be independently checked from equation (8a). This angle of twist remains unchanged during the subsequent inelastic translation of the diaphragm in the y direction by $\left(\mu_{\Delta}-1\right) \Delta_{y}$, as seen in Figure 9(b). The ultimate displacements for the walls can thus be determined. For example from Figure $9 \mathrm{~b}$ for the wall with the smallest yield displacement

$$
\Delta_{\mathrm{u} 1}=\Delta_{\mathrm{y} 1}+\left(\mu_{\Delta}-1\right) \Delta_{\mathrm{y}}
$$

Thus the ductility demand imposed on Wall (1), found to be critical, is

$$
\mu_{1}=\mu_{\max }=\frac{\Delta_{\mathrm{u} 1}}{\Delta_{\mathrm{y} 1}}=1+\left(\mu_{\Delta}-1\right) \frac{\Delta_{\mathrm{y}}}{\Delta_{\mathrm{y} 1}}
$$

The important parameter affecting the relationship between the element $\left(\mu_{\max }\right)$ and system $\left(\mu_{\Delta}\right)$ ductility factors, is the ratio $\Delta_{\mathrm{y}} / \Delta_{\mathrm{y} 1}$, where $\Delta_{\mathrm{y} 1}=\Delta_{\mathrm{y}, \min }$.

From the displacement pattern shown in Figure 9b, the yield displacement for the system at the location of CM may be derived from simple geometrical relationships such as

$$
\Delta_{\mathrm{y}}=0.5\left(\Delta_{\mathrm{yl}}+\Delta_{\mathrm{y} 3}\right)-\mathrm{e}_{\mathrm{mx}} \theta_{\mathrm{tu}}
$$

where $\mathrm{D}$ is the distance between the extreme translating elements, as shown in Figure 3a. For the structure in Figure $9 \mathrm{a}, \mathrm{D}=\mathrm{A}$. If $\mathrm{CM}$ does not coincide with the centre of the plan, its position, as shown in Figure $3 \mathrm{~d}$, is defined, by the mass eccentricity, $e_{m x}$, with respect to the y axis. However, a more direct and simpler approach is to quantify the system yield displacement, $\Delta_{y}$, at $\mathrm{CM}$ from equation (3a) thus:

$$
\Delta_{\mathrm{m}}=\Delta_{\mathrm{y}}=\frac{\mathrm{V}_{\mathrm{Ey}}}{\mathrm{K}_{\mathrm{sy}}}
$$

The important relationship between the ductility capacity of the critical element, $\mu_{\max }$, and the system displacement ductility demand, $\mu_{\Delta}$ for convenience expressed in the form of equation (6a), is then found from equation (14) thus

$$
\mu_{\Delta}=\frac{\mu_{\max }-1}{1+\omega_{\operatorname{tr}}}+1
$$

where

$$
\begin{aligned}
& \omega_{\mathrm{tr}}=\frac{\Delta_{\mathrm{y}}}{\Delta_{\mathrm{y} 1}}-1 \\
& \frac{\Delta_{\mathrm{y}}}{\Delta_{\mathrm{y} 1}}=\frac{\mathrm{V}_{\mathrm{Ey}}}{\mathrm{K}_{\mathrm{sy}}} \frac{\mathrm{k}_{1}}{\mathrm{~V}_{1}}
\end{aligned}
$$

is the most important property of the elastic structure affecting its inelastic torsional response. $\mathrm{K}_{\mathrm{sy}}$ is the translational stiffness of the structure defined for this particular direction by equation (3c). It includes the effect of elastic twist upon translational stiffness.

All the constituent components of the factor $\omega_{\mathrm{tr}}$ will have been obtained by the designer in previous calculations leading up to this stage. Hence from equations (8a) and (15) and with $\Delta_{\mathrm{y} 1}=$ $\mathrm{V}_{1} / \mathrm{k}_{1}$, the $\omega$ factor may be also determined from:

$$
\begin{aligned}
\omega_{\mathrm{tr}} & =\left(0.5-\frac{\mathrm{e}_{\mathrm{mx}}}{\mathrm{D}}\right) \frac{\mathrm{e}_{\mathrm{vx}} \mathrm{V}_{\mathrm{Ey}}}{\lambda_{\mathrm{ty}} \mathrm{K}_{\mathrm{t}}} \frac{\mathrm{k}_{1}}{\mathrm{~V}_{1}} \mathrm{D} \\
& =\left(0.5-\frac{\mathrm{e}_{\mathrm{mx}}}{\mathrm{D}}\right)\left(\frac{\mathrm{k}_{1}}{\lambda_{\mathrm{ty}} \mathrm{K}_{\mathrm{t}} / \mathrm{D}^{2}}\right)\left(\frac{\mathrm{e}_{\mathrm{vx}}}{\mathrm{D}}\right)\left(\frac{\mathrm{V}_{\mathrm{Ey}}}{\mathrm{V}_{1}}\right)
\end{aligned}
$$

When there is no torsion, ie, when $\mathrm{e}_{\mathrm{vx}}=0, \omega_{\mathrm{tr}}=0$ and hence from equation (17) $\mu_{\Delta}=\mu_{\max }$. The subscript tr intends to indicate that the factor is relevant to torsional restrained systems.

For design purposes the most convenient expression results from the combination of equations (18) and (19). thus

$$
\omega_{\mathrm{tr}}=\frac{\mathrm{k}_{1}}{\mathrm{~K}_{\mathrm{s}}} \frac{\mathrm{V}}{\mathrm{V}_{1}}-1
$$

and designer may prefer to use it. The translational stiffness with reference to $C M, K_{s}$, is given by equation (3c). Note that for the illustrative example chosen (Figure 9b) $\Delta_{\mathrm{y} 1}=\mathrm{V}_{1} / \mathrm{k}_{1}<$ $\mathrm{V}_{3} / \mathrm{k}_{3}=\Delta_{\mathrm{y} 3}$ 


\subsection{Torsionally Unrestrained Systems $\left(\lambda_{t}=0\right)$}

In torsionally unrestrained systems, such as illustrated in Figure 3 , allowance must be made for the fact that inelastic torsional displacements will mobilise the ductility of one element only. Thereby the ductility demand on that element will be greatly increase. This type of structure was considered in Section 3.4 where it was shown by equation ( $6 \mathrm{a})$ that the relation between the system ductility capacity, $\mu_{\Delta}$, and that of the yielding element, $\mu_{\max }$, such as Wall 2 in Figure 3, takes the same form as equation (19) with the factor $\omega_{t r}$ modified to $\omega_{0}$, given by equations (6b) and (6c).

\subsection{Existing Structures}

When a diagnostic analysis of the expected performance of an existing structure is undertaken, the probable strength, $V_{p i}$, stiffness, $\mathrm{k}_{\mathrm{i}}$, mass eccentricity, $\mathrm{e}_{\mathrm{m}}$, and ductility capacity, $\mu_{\mathrm{i} \text {, max }}$ of elements will be estimaied and taken as known. The probable strength of the elements, $\mathrm{V}_{\mathrm{pi}}$, provided will differ from these that would be predicted by a conventional analysis of the elastic system. Therefore the design procedure suggested in Section 6.1 for torsionally restrained systems can be considered only as an approximation. Differences and acceptable approximations are discussed here, for convenience again in relation to the structure shown in Figure 9a. The examination is set out in a few steps.

Step 1: When the stiffness, $\mathrm{k}_{\mathrm{i}}$, and the probable strength, $\mathrm{V}_{\mathrm{pi}}$, of each element with respect to the $\mathrm{y}$ direction is evaluated. The positions of $\mathrm{CR}$ and $\mathrm{CV}$ are found. Hence the strength eccentricity with respect to $\mathrm{CM}$, such as $e_{v x}$, is determined. Therefore the torque produced by the base shear, $V_{p y}=V_{p 1}+V_{p 3}$, in the $y$ direction is also established as $e_{\mathrm{vx}} \mathrm{V}_{\mathrm{py}}$.

Step 2: The torsional restraint is provided only by the elastic elements, such as Walls (2) and (4) in Figure 9a. The associated torsional stiffness $\lambda_{\mathrm{ty}} \mathrm{K}_{\mathrm{t}}$ can be derived without having to consider the ductile elements. In the case of the example structure this is:

$$
\lambda_{\text {ty }} K_{t}=\frac{k_{2} k_{4}}{k_{2}+k_{4}} A^{2}=0.21 A^{2}
$$

As Example $\mathrm{A}$ of the Appendix shows (A1), this corresponds to $\lambda_{\mathrm{ty}}=0.5$. The angle of twist, $\theta_{\mathrm{tu}}$, is found from equation (8a).

Step 3: As previous discussions have indicated, the ductility capacity of torsionally restrained systems is governed by the ductility demand on the element, with the smallest yield displacement, such as Wall (1). Because the relative strength of the elements differs from that predicted by the analysis of the elastic structure, the translational elements (Walls (1) and (3)) will not commence yielding simultaneously. Therefore, the yield displacement of the system, $\Delta_{\mathrm{y}}$ measured at CM, cannot be uniquely defined. It needs to be approximated, using equation (15), where the value of $\theta_{\mathrm{tu}}$ is used as found in Step (2). Hence with relevant values of $\Delta_{\mathrm{y}}$ and $\Delta_{\mathrm{y} 1}=\mathrm{V}_{\mathrm{p} 1} / \mathrm{k}_{1}, \omega_{\mathrm{tr}}$ given by equation (18) is estimated, and hence the approximate system displacement capacity is obtained from equation (17), modified thus:

$$
\mu_{\Delta}=\frac{3 V_{\text {py }}}{4 V_{\text {Ey }}}\left(\frac{\mu_{\max }-1}{1+\omega_{\text {tr }}}+1\right) \leq \mu_{\max }
$$

where $\mathrm{V}_{\mathrm{Ey}}$ is the value corresponding to that derived from code [1] specified spectra. The system stiffness, $\mathrm{K}_{\mathrm{sy}}$, used in deriving the period of vibration of the structure, is that given by equation (3c). The ratio $3 V_{p y} / 4 V_{E y}$ intends to recognise the beneficial effect of excess strength of an existing system by suggesting an increased system displacement ductility capacity when the probable strength of the structure, $\mathrm{V}_{\mathrm{py}}$, is more than $1.33 \mathrm{~V}_{\mathrm{Ey}}$.

If $\mu_{\Delta}$ from equation (21), using $\mathrm{V}_{\mathrm{Ey}}$ based on this value of $\mu_{\Delta}$, is larger than that derived from the relevant spectra, the existing system has reserve displacement ductility capacity.

It should be noted that the ductility capacity of critical elements, $\mu_{i, \max }$, may be less than that expected for members detailed in accordance with current code [3] requirements. It may then be found that the system displacement ductility capacity, given by equation (21), does not satisfy code requirements.

\section{CONCLUSIONS}

A rational and very simple design approach addressing torsional response and based on force-displacement relationships is postulated. The terms used are very familiar to structural design practitioners. When torsion is present the ductility demand, $\mu_{\max }$, on some elements will be inevitably larger than the system ductility demand, $\mu_{\Delta}$

The reference yield displacement for a structural system, $\Delta_{y}$, depends on the properties, such as translatory stiffness, $\mathrm{k}_{\mathrm{i}}$, of the elastic components, as well as structure geometry. Therefore, the ultimate relationship between the maximum element ductility capacity, $\mu_{\max }$, and that of the system, $\mu_{\Delta}$, combine properties relevant to both elastic and inelastic response.

To eliminate in ductile structures possibly adverse effects of excessive twist, some residual torsional restraint should be provided by elastic elements, while overstrengths under imposed inelastic translational displacements are being developed in other elements.

Instead of a relatively involved dynamic analysis to assess the ductile response of systems affected by torsion, a procedure, based on the use of equivalent static forces, amenable for routine design office practice and addressing displacement control, is suggested.

In torsionally restrained systems the maximum ductility demand arises in the element with lowest yield displacement, $\Delta_{\mathrm{yi}}=$ $\mathrm{V}_{\mathrm{i}} / \mathrm{k}_{\mathrm{i}}$. Hence this element will control the displacement ductility capacity, $\mu_{\Delta}$, of the system.

In a system with some torsional restraint, transient critical earthquake attacks may occur along one of the diagonals with respect to the orthogonal framing of the plan.

The degree of torsional restraint and hence the torsional design forces acting on elements at the ultimate limit state, is best 
based on the location of the "centre of resistance "or" centre of strength", CV, in relation to the "centre of mass", CM.

In quantifying system stiffness and displacement ductilities, the reference yield displacement, $\Delta_{y}$, should be that at the "centre of mass", CM.

As long as torsional response is restrained by elastic lateral force-resisting elements, with a reasonable amount of reserve strength, torsional inertia effects are not likely to effect significantly ductility demands on critical translatory elements.

With some modifications the principles enumerated apply also to buildings in which lateral force resistance in two principal orthogonal directions is provided by ductile frames alone.

The suggested assessment of torsional response may be applied also to one storey dual systems. However, dual systems in which multistorey frames and walls interact, have as yet not been subjects of this study. Their response is complex [2]. They offer exciting challenges to researchers.

Existing codified procedures used in most countries, as those in New Zealand, and based on elastic structural response, including limitation on the angle of twist, should be considered being largely irrelevant to ductile structural response. Critical aspects of torsional response, which are associated with dominant displacements along a diagonal of the framing system, are not known to have been addressed in building codes.

When several parallel elements at different planes, as in multibay framed buildings, resist the lateral forces, the assessment of the system ductility capacity, $\mu_{\Delta}$, may be based on the deformations imposed on elements situated at the boundaries of the floor plan. Illustrative examples of this have not been given here.

As long as no significant identifiable eccentricities exist in redundant structural systems with negligible residual torsional restraint, response associated with diagonal base shear may not be critical. The reasons for this are that, the development of enhanced base shear resistance in this direction can be expected to result in reduced displacement ductility demands, and the randomness of oscillatory motions is likely to be coupled only with rare and transient instants, at which large ductility demands would coincide with the critical diagonal direction.

Particularly critical ductility demands on lateral force-resisting elements may arise in systems in which negligible or no torsional restraint has been provided.

The principles presented are equally applicable to force-and displacement-based design approaches.

The evaluation of torsional response presented here was based on the traditional concepts of stiffness and strength, widely used in routine design as illustrated in Figure 8. It implied that element stiffness, $\mathrm{k}_{\mathrm{i}}$, and strength, $\mathrm{S}_{\mathrm{i}}$, are independent quantities. A more realistic evaluation of the response of ductile reinforced concrete elements should, however, take into account also the effect of strength on stiffness. The effects of this feature on the torsional response of ductile buildings is being studied.

\section{RECOMMENDATIONS FOR DESIGN}

Instead of accepting a given stiffness eccentricity in the seismic design of structures, the designer should aim to reduce, or preferably eliminate, predictable eccentricities.

Eccentricities may be reduced by selecting more suitable stiffnesses of lateral force- resisting vertical elements, for example by subdividing particularly stiff elements into components with reduced stiffness [7]. The best cure for torsional problems is the elimination of the cause, excessive eccentricity.

When identifiable eccentricities with respect to the "centre of mass", CM, exist, the design system ductility demand, $\mu_{\Delta}$, may need to be reduced, in some cases significantly, to ensure that the ductility capacity of critical elements, $\mu_{\max }$, is not exceeded It was shown that the relevant relationship is

$$
\mu_{\Delta} \leq \frac{3}{4} \frac{\mathrm{V}_{\mathrm{p}}}{\mathrm{V}_{\mathrm{E}}}\left[\frac{\mu_{\max }-1}{1+\omega}+1\right]
$$

were the value of the factor $\omega$ is given for:

(i) torsionally restrained systems $\left(\omega_{\mathrm{tr}}\right)$ by equations (18) or $(20 a)$ or $(20 b)$,

(ii) torsionally unrestrained systems by $\left(\omega_{0}\right)$ equations $(6 b)$ or $(6 c)$ or $(6 d)$,

and where the maximum ductility capacity, $\mu_{\max }$, of the critical element may be assumed in:

(a) torsionally restrained systems 1.2 times the value specified by relevant materials codes [3]. This concession is consistent with the allowances made for the inelastic-redistribution in redundant systems of design actions derived from analysis of the elastic structure, whereby an inevitable increase of ductility demand on affected elements is recognised (Figure 8) [2],

(b) torsionally unrestrained systems with the above concession of $20 \%$ increase not used,

(c) all elements to be in accord with relevant quality of the detailing [3] of the potential plastic wing regions.

and where $V_{p} / V_{E}$ is the ratio of the probable system strength to the corresponding value of the base shear, derived from the appropriate design spectrum. When capacity design procedures are used the typical value of $\mathrm{V}_{\mathrm{p}} / \mathrm{V}_{\mathrm{E}}$ is $\psi_{\mathrm{o}} / 1.1$, where $\psi_{0}$ is the system overstrength factor [2].

When the $20 \%$ increase in the maximum element displacement is admissible, in accordance with (a) above, the full system displacement ductility capacity, $\mu_{\Delta}$, may be relied on provided that the value of $\omega_{\mathrm{tr}}$ in equation (22) does not exceed 0.25 .

Current codified provisions $[1,2]$ which are based on elastic structural response, should be considered when the design aim is to satisfy performance criteria associated with the serviceability limit state. No attention should need to be given to current requirements [1,2] for accidental torsion or limitations on elastic twist, such as given in Figure 2, when design addresses ductile seismic response satisfying criteria of the ultimate limit state. 
The lack or absence of torsional restraint necessitates limitations on system displacement ductility demands. However, critical elements must be expected to be subjected to the maximum ductility demands envisaged for the particular type of element $[1,3]$. Therefore, the relaxations in the requirements of NZS 3101:1995[3] for structural systems of limited ductility, particularly those for the detailing elements of limited ductility are not applicable!

The proposed procedure is well suited for diagnostic evaluation of the likely torsional response of existing structures. It may well be that, when required, the strengthening and stiffening of those vertical elements which provide torsional restraint will be more effective than the strengthening of translational elements on which additional ductility demands may be imposed because of excessive twist of the system [7].

For torsionally unrestrained systems the proposed design approach leads to criteria more severe than those embodied in existing codes [1]. However, less severe requirements may be expected when substantial torsional restraint is present, as encountered in the great majority of buildings.

\section{ACKNOWLEDGEMENTS}

The generous assistance with some of the computational work of $\mathrm{F}$ Crisafulli and the extensive constructive comments of Professors $\mathrm{H}$ Bachmann of the Swiss Federal Institute of Technology in Zürich and W K Tso of McMaster University, Hamilton, Canada are gratefully acknowledged.

\section{REFERENCES}

1 Standard Association of New Zealand, 1992. Code of Practice for General Structural Design Loadings for Buildings, NZS 4203:1992, Wellington.

2 Paulay, T and MJN Priestley, 1992. Seismic design of reinforced concrete and masonry structures, John Wiley and Sons, pp 767.

3 Standards New Zealand, NZS 3101:1995. Concrete Structures Standard Part 1 -The design of concrete structures, pp 256, Part 2-Commentary on the design of concrete structures, pp 264.

Tso, W K and C M Wong, 1993. An evaluation of the New Zealand code torsional provision, Bulletin of the New Zealand National Society for Earthquake Engineering, 26(2):194-207.

5 Architectural Institute of Japan, 1994. AIJ Structural Design Guidelines for Reinforced Concrete Buildings", Tokyo, pp 207.

European Committee for Standardisation, 1993. Eurocode 8 - Design Provisions for Earthquake Resistance of Structures, Lisbon.

7 De La Llera, Juan and Anil Chopra, 1995. Understanding of inelastic seismic behaviour of asymmetric - plan buildings, Earthquake Engineering and Structural Dynamics, 24:549-572.

\section{APPENDIX}

\section{Example A}

A1 Determine the maximum acceptable displacement ductility capacity of the torsionally restrained structure, $\mu_{\Delta}$, shown in Figure 9a, if the assumed ductility capacity of the critical walls $\mu_{\max }=1.2 \times 5=6.0$ is not to be exceeded. The base shear to be considered is $\mathrm{V}_{\mathrm{y}}(\alpha=0)$. Some features of the behaviour of this structure are discussed in Section 4.1.

Properties:

Stiffnesse

Eccentricity

$$
\begin{aligned}
& \mathrm{k}_{1}=\mathrm{k}_{2}=0.7 ; \quad \mathrm{k}_{3}=\mathrm{k}_{4}=0.3 \\
& \mathrm{e}_{\mathrm{rx}}=-0.2 \mathrm{~A} \quad \text { (Figure 9a) }
\end{aligned}
$$

Forces and Ductilities.

$\mathrm{V}_{1}=0.7 \mathrm{~V}_{\mathrm{y}}-0.2 \mathrm{AV} \mathrm{V}_{\mathrm{y}} \times 0.7 \times 0.3 \mathrm{~A} / 0.42 \mathrm{~A}^{2}=0.6 \mathrm{~V}_{\mathrm{y}}$

$\mathrm{V}_{3}=\quad=0.4 \mathrm{~V}_{\mathrm{y}}$

Hence the location of $\mathrm{CV}$ is such that:

$$
\begin{aligned}
& \mathrm{e}_{\mathrm{vx}}=(0.4-0.6) 0.5 \mathrm{AV}_{\mathrm{y}} / \mathrm{V}_{\mathrm{y}}=0.1 \mathrm{~A} \\
& \mathrm{D}=\mathrm{A} ; \mathrm{e}_{\mathrm{vx}} / \mathrm{D}=0.1
\end{aligned}
$$

The residual torsional restraint is quantified by $\lambda_{\text {ty }}=0.5$. From equation (20a) with D replaced by $A$ :

$$
\begin{aligned}
\omega_{\mathrm{tr}} & =0.5\left(\frac{\mathrm{k}_{1}}{\lambda_{\mathrm{ty}} \mathrm{K}_{\mathrm{t}} / \mathrm{A}^{2}}\right)\left[\frac{\mathrm{e}_{\mathrm{vx}}}{\mathrm{A}}\right]\left(\frac{\mathrm{V}_{\mathrm{y}}}{\mathrm{V}_{1}}\right) \\
& =0.5 \frac{0.7}{0.5 \times 0.42} \times 0.1 \times \frac{1}{0.6}=0.278
\end{aligned}
$$

Hence from equation (22), assuming that $3 \mathrm{~V}_{\mathrm{p}} / 4 \mathrm{~V}_{\mathrm{E}}=1$,

$$
\mu_{\Delta}=\frac{6.0-1}{1+0.278}+1=4.91 \approx 5
$$

From the appropriate design spectrum the intensity of $\mathrm{V}_{\mathrm{y}}$ may now be selected.

\section{Checking}

The above result may be conveniently verified, using relevant displacements, as follows (See Figure 9b).

$$
\begin{aligned}
& \Delta_{\mathrm{y} 1}=\mathrm{V}_{1} / \mathrm{k}_{1}=0.6 \mathrm{~V}_{\mathrm{y}} / 0.7=0.857 \mathrm{~V}_{\mathrm{y}} \\
& \Delta_{\mathrm{y} 3}=\mathrm{V}_{3} / \mathrm{K}_{3}=0.4 \mathrm{~V}_{\mathrm{y}} / 0.3=1.333 \mathrm{~V}_{\mathrm{y}} \\
& \Delta_{\mathrm{y}}=0.5\left(\Delta_{\mathrm{y} 1}+\Delta_{\mathrm{y} 2}\right)=1.095 \mathrm{~V}_{\mathrm{y}}
\end{aligned}
$$

The angle of twist is: $\theta_{\mathrm{t}}=(0.857-1.333) \mathrm{V}_{\mathrm{y}} / \mathrm{A}$

or from equation (8a)

$$
=-0.476 \mathrm{~V}_{\mathrm{y}} / \mathrm{A}
$$

$\theta_{\mathrm{tu}}=-\frac{\mathrm{e}_{\mathrm{vx}} \mathrm{V}_{\mathrm{y}}}{\lambda_{\mathrm{ty}} \mathrm{K}_{\mathrm{t}}}=-\frac{0.1 \mathrm{AV}_{\mathrm{y}}}{0.5 \times 0.42 \mathrm{~A}^{2}}=-0.476 \mathrm{~V}_{\mathrm{y}} / \mathrm{A}$

Inelastic displacement of CM: $\quad \Delta_{\mathrm{u}}=\left(\mu_{\Delta}-1\right) \Delta_{\mathrm{y}}$ 
Ultimate displacement of Wall (1) when $\mu_{\Delta}=4.91$

$$
\begin{aligned}
\Delta_{\mathrm{u} 1} & =\Delta_{\mathrm{y} 1}+\left(\mu_{\Delta}-1\right) \Delta_{\mathrm{y}} \\
& =(0.857+3.91 \times 1.095) \mathrm{V}_{\mathrm{y}}=5.14 \mathrm{~V}_{\mathrm{y}}
\end{aligned}
$$

Hence $\mu_{1}=5.14 / 0.857=6.0$ as specified.

The most convenient approach is with the use of equation (20b). Therefore, from equation (3c), giving the system stiffness, and with $\mathrm{e}_{\mathrm{rx}}=0.2 \mathrm{~A}$ and from equation (2c)

$$
\begin{gathered}
\mathrm{r}_{\mathrm{kx}}^{2}=\mathrm{K}_{\mathrm{t}} / \Sigma \mathrm{k}_{\mathrm{yi}}=0.42 \mathrm{~A}^{2}: \\
\mathrm{K}_{\mathrm{sy}}=\frac{\sum \mathrm{k}_{\mathrm{yi}}}{1+\left(\frac{\mathrm{e}_{\mathrm{rx}}}{\mathrm{r}_{\mathrm{kx}}}\right)^{2}}=\frac{0.7+0.3}{1+\frac{0.2^{2}}{0.42}}=0.913 \\
\Delta_{\mathrm{y}}=\frac{\mathrm{V}_{\mathrm{y}}}{\mathrm{K}_{\mathrm{sy}}}=\frac{\mathrm{V}_{\mathrm{y}}}{0.913}=1.095 \mathrm{~V}_{\mathrm{y}} \text {, as above }
\end{gathered}
$$

From equation $20 \mathrm{~b}$

$$
\omega_{\mathrm{tr}}=\frac{\mathrm{k}_{1}}{\mathrm{~K}_{\mathrm{sy}}} \frac{\mathrm{V}_{\mathrm{y}}}{\mathrm{V}_{\mathrm{l}}}-1=\frac{0.7 \times 1.0}{0.913 \times 0.6}-1=0.278 \text {, as above }
$$

The ductility demand on Wall 3 is not critical and this may be also readily verified (See' Figure 9b).

$$
\mu_{3}=\frac{\Delta_{\mathrm{y} 3}+\left(\mu_{\Delta}-1\right) \Delta_{\mathrm{y}}}{\Delta_{\mathrm{y} 3}}=\frac{1.333+3.91 \times 1.095}{1.333}=4.21<5
$$

A2 Assume that Walls (2) and (4) in the example structure of Figure $9 \mathrm{a}$ have been replaced by very flexible elements. Assuming a total absence of torsional restraint and that Wall 3 will not yield, using equation (6c) when $e_{m}=0$ :

Hence

$$
\omega_{\mathrm{o}}=0.7 / 0.3(1)^{2}=2.33 ; \mu_{\max }=5
$$

$\mu_{\Delta}=1(5-1) /(1+2.33)+1=2.2$ from equation $(22)$.

When only Wall 1 yields, $\mu_{\Delta}=3.8>2.2$. This example demonstrates the very signiciant benefits derived from the presence of torsional restraint.

\section{Example B}

To illustrate the application of the design approach embodied in equation (22), the example structure shown in Figure B is briefly studied here. Walls (1) and (2) are assumed to be identical. The example represents a special but not uncommon arrangement of lateral force resisting elements. The torsional restraint provided is direction dependent. It is evident that a significant eccentricity, both in terms of stiffness (CR) and strength $(\mathrm{CV})$, with respect to the position of the base shear, $\mathrm{V}_{\mathrm{x}}$, (CM) is present. As Figure $\mathrm{B}$ shows it is assumed that $\mathrm{k}_{3} / \mathrm{k}_{1}=8$.

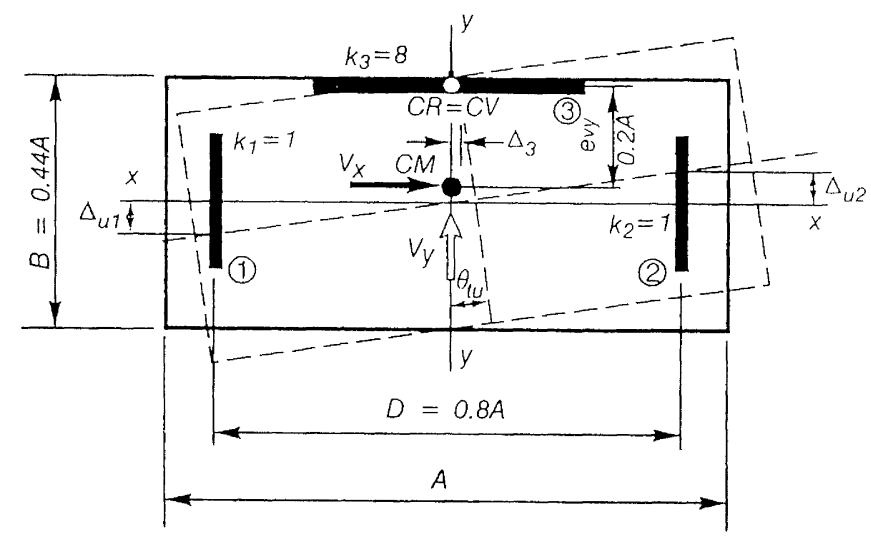

FIGURE B An example structure with direction dependent torsional restraint.

B1 Under the action of the base shear, $V_{y}$, the system is identical to that shown in Figure 3a. In terms of ductile response, there is no torsional restraint. Hence $\lambda_{t}=0$. Therefore in equation (22), $\omega=\omega_{0}$, given by equation (6b), is applicable. By allowing for a possible variation of the position of $\mathrm{CM}$ in the $\mathrm{x}$ direction by $\pm 0.05 \mathrm{~A}$, and assuming that $\mu_{\max }$ $=5$, we find that with $\mathrm{e}_{\mathrm{m}} / \mathrm{D}=0.05 / 0.8=0.063, \omega_{0}=1$ $(0.563 / 0.437)^{2}=1.66$ and hence

$$
\mu_{\Delta}=\frac{5-1}{1+1.66}+1=2.5
$$

With $\mathrm{e}_{\mathrm{m}}=0$ assumed, $\omega_{0}=1$ and $\mu_{\Delta}=3.0$. This suggests that the cautious assumption made for "accidental" eccentricity is hardly warranted.

B2 When considering a base shear in the $\mathrm{x}$ direction, two cases need to be examined, depending on whether Wall (3) or Walls (1) and (2) will yield first. The criteria is defined simply by the relationship

$$
\mathrm{V}_{3} / \mathrm{V}_{1} \quad \mathrm{D} / \mathrm{e}_{\mathrm{vy}}
$$

When the strength of Walls (1) and (2) is such that

$$
\mathrm{V}_{1}=\mathrm{V}_{2} \geq \lambda_{\mathrm{o}}\left(\mathrm{e}_{\mathrm{vy}} / \mathrm{D}\right) \mathrm{V}_{3}
$$

the overstrength of Wall (3) associated with the inelastic displacements in the $\mathrm{x}$ direction can be developed. $\lambda_{0}$ is the overstrength factor with respect to the nominal flexural strength of this wall. It is usually of the order of 1.25 . Because Walls (1) and (2) are assured of remaining elastic, the full torsional restraint of the system is retained. However, response must take into account the absolute magnitude of this restraint. 
For this structure, previously not considered in detail, it is best to derive the value of the important parameter, $\omega$, from equation (20b), which defines the elastic properties of the structure subjected to torsion. To this end the displacements, $\Delta_{\mathrm{y}}$ and $\Delta_{\mathrm{y} 3}$ are required.

From equation (2e) $\mathrm{K}_{\mathrm{t}}=2 \times 1(0.5)^{2}=0.5 \mathrm{D}^{2}$ equation (2c) $\mathrm{r}_{\mathrm{ky}}^{2}=\mathrm{K}_{\mathrm{t}} / \mathrm{k}_{3}=0.5 \mathrm{D}^{2} / 8=0.063 \mathrm{D}^{2}$.

Assume a decision eccentricty of

$$
\begin{aligned}
\mathrm{e}_{\mathrm{ry}} & =\mathrm{e}_{\mathrm{vy}}=0.2 \mathrm{~A}=0.25 \mathrm{D} \\
\text { Hence } & \left(\mathrm{e}_{\mathrm{ry}} / \mathrm{r}_{\mathrm{ky}}\right)^{2}=0.25^{2} / 0.063=0.99
\end{aligned}
$$

It may be noted that this ratio is more than 6 times larger than the limitation suggested by Eq. (2b).

From equation (3c) the stiffness of the system is:

$$
\mathrm{K}_{\mathrm{sx}}=8 /(1+0.99)=4.02
$$

This indicates that the stiffness of the system is only $50 \%$ of that of Wall 3 .

Hence from equation (20b):

$$
\omega_{\mathrm{tr}}=\frac{8}{4.02} \frac{1}{1}-1 \approx 1
$$

and equation (22) with $3 \mathrm{~V}_{\mathrm{p}} / 4 \mathrm{~V}_{\mathrm{E}}=1$

$$
\mu_{\Delta} \geq \frac{5-1}{1+1}+1 \approx 3.0
$$

B3 When it is found that $V_{1}=V_{2}<\left(1 / \lambda_{0}\right)\left(e_{v y} / D\right) V_{3}$, Wall (3) will remain elastic and hence inelastic response will be associated with only twisting of the system. Theoretically the centre of twist should remain at the location of CR and CV, as shown in Figure B, when Walls (1) and (2) sustain a displacement ductility demand of up to $\mu_{\max }=5$ simultaneously in opposite directions. It is estimated that the strength ratio is $\mathrm{V}_{3} / \mathrm{V}_{1}=6$. The limitation on the system displacement capacity, $\mu_{\Delta}$, is derived here from first principles.
Because the translational stiffness of the structure in the $x$ direction depends on the properties of the elastic structure and the stiffness eccentricity, $e_{\mathrm{ry}}$, it is the same as that derived above, ie, $K_{s x}=4.02$. If the strength of Walls (1) and (2) is $\mathrm{V}_{1,2}$ and $\mathrm{e}_{\mathrm{ry}}=\mathrm{e}_{\mathrm{vy}}=0.25 \mathrm{D}$, as before, from equilibrium

$$
\mathrm{V}_{3}=\mathrm{V}_{\mathrm{x}}=\mathrm{DV}_{1,2} / 0.25 \mathrm{D}=4.0 \mathrm{~V}_{1,2}<6 \mathrm{~V}_{1,2}
$$

Hence the yield displacement of the system at $C M$ in the $x$ direction is

$$
\Delta_{\mathrm{yx}}=\mathrm{V}_{\mathrm{x}} / \mathrm{K}_{\mathrm{sx}}=0.995 \mathrm{~V}_{1,2}
$$

The additional inelastic displacement at $\mathrm{CM}$ in the $\mathrm{x}$ direction, $\Delta_{\mathrm{mpx}}$, resulting from the maximum post-yield deformations of Walls (1) and (2), $\left(\mu_{\max }-1\right) \Delta_{\mathrm{y} 1}$, is

$$
\Delta_{\mathrm{mpx}}=0.25 \mathrm{D} \theta_{\mathrm{tp}}
$$

where the post-yield twist is: $\theta_{\mathrm{tp}}=\frac{\left(\mu_{\max }-1\right) \Delta_{\mathrm{y} 1}}{0.5 \mathrm{D}}$

Hence $_{\Delta_{\mathrm{mpx}}}=\frac{0.25 \mathrm{D}\left(\mu_{\max }-1\right)}{0.5 \mathrm{D}} \frac{\mathrm{V}_{1,2}}{1}=\left(\mu_{\Delta}-1\right) \Delta_{\mathrm{yx}}$

and thus the system displacement ductility capacity is reduced to

$\mu_{\Delta}=\frac{\mu_{\max }-1}{2} \frac{\mathrm{V}_{1,2}}{\mathrm{~V}_{\mathrm{x}}} \mathrm{K}_{\mathrm{sx}}+1=\frac{5-1}{2} \times \frac{1}{4} \times 4.02+1=3.01$ 